\title{
A Review of Virtual Reality Based Training Simulators for Orthopaedic Surgery
}

ARTICLE in MEDICAL ENGINEERING \& PHYSICS · DECEMBER 2015

Impact Factor: 1.83 · DOI: 10.1016/j.medengphy.2015.11.021

READS

166

4 AUTHORS, INCLUDING:

Neil Vaughan

Bournemouth University

30 PUBLICATIONS 26 CITATIONS

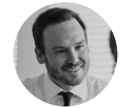

Tom Wainwright

Bournemouth University

24 PUBLICATIONS 55 CITATIONS

SEE PROFILE

SEE PROFILE 


\title{
A Review of Virtual Reality Based Training Simulators for Orthopaedic Surgery
}

\author{
Neil Vaughan ${ }^{1 *}$, Venketesh N. Dubey ${ }^{1}$ \\ ${ }^{1}$ Bournemouth University, Faculty of Science and Technology, United Kingdom. \\ Thomas W. Wainwright ${ }^{2,3}$, Robert G. Middleton ${ }^{2,3}$ \\ ${ }^{2}$ Royal Bournemouth Hospital NHS Foundation Trust, United Kingdom. \\ ${ }^{3}$ Bournemouth University, Faculty of Health and Social Sciences, United Kingdom.
}

\begin{abstract}
This review presents current virtual reality based training simulators for hip, knee and other orthopaedic surgery, including elective and trauma surgical procedures. There have not been any reviews focussing on hip and knee orthopaedic simulators. A comparison of existing simulator features is provided to identify what is missing and what is required to improve upon current simulators. In total 11 total hip replacement pre-operative planning tools were analysed, plus 9 hip trauma fracture training simulators. Additionally 9 knee arthroscopy simulators and 8 other orthopaedic simulators were included for comparison. The findings are that for orthopaedic surgery simulators in general, there is increasing use of patient-specific virtual models which reduce the learning curve. Modelling is also being used for patient-specific implant design and manufacture. Simulators are being increasingly validated for assessment as well as training. There are very few training simulators available for hip replacement, yet more advanced virtual reality is being used for other procedures such as hip trauma and drilling. Training simulators for hip replacement and orthopaedic surgery in general lag behind other surgical procedures for which virtual reality has become more common. Further developments are required to bring hip replacement training simulation up to date with other procedures. This suggests there is a gap in the market for a new high fidelity hip replacement and resurfacing training simulator.
\end{abstract}

Keywords: Orthopaedic, Hip replacement, Resurfacing, Simulator, Haptics, Modelling

\section{Introduction}

This article reviews current virtual reality (VR) based training simulators for hip replacement and resurfacing, with comparison to other areas of orthopaedic surgery simulation. A comparison of the simulator features is provided to identify what is missing and what is required to improve upon current simulators.

There have not been any reviews focusing on hip surgery training simulators. It is likely that in the near future hip surgery simulation could become a focus area for new development to catch up with other surgical training procedures.

Simulators for orthopaedic surgery lag behind other surgical disciplines [1]. In the past two decades there has been very little research attempting to create an orthopaedic surgery simulator, and even fewer studies attempting to validate orthopaedic simulators. More simulation needs to be done in orthopaedics, as trainees are getting more exposed to computers and laboratory training [2]. Spinal simulation training is still in its infancy. Simulators for orthopaedic surgery provide an important training tool. Currently training simulators are only available to a select few trainees who have to register for courses and workshops to do simulation for specific procedures.

There is a lack of training simulators for total hip replacement, which may be due to the relatively long length of the procedure taking around 60-90 minutes to complete. The keys steps in the hip replacement procedure are acetabular reaming, fixation of acetabulum cup, broaching the femoral canal and placement of the stem. Reviews recommend that simulation is also an excellent way to teach arthroscopy skills, which are a different skill set than open orthopaedic surgery [3]. A review [4] identified 19 existing arthroscopy simulators (9 shoulder, 9 knee, and 1 hip) showing arthroscopy is a popular field for simulator training.

\footnotetext{
* Corresponding author at: Bournemouth University, Faculty of Science, Engineering and Technology, Fern Barrow, Poole, United Kingdom. Tel.: +44 1202965038. E-mail address: nvaughan@bmth.ac.uk (N. Vaughan).
} 
Hip joint replacement has been considered to be the most successful and influential orthopaedic surgery of the twentieth century. Currently over 66,000 total hip replacements (THR) are performed each year in England and Wales by the National Health Service (NHS) and around 75,000 hip fractures are treated each year in the UK [5]. Knee arthroscopy has increased 49\% between 1996-2006 and now over 1 million are performed each year.

An increasing number of orthopaedic procedures are required annually, due to the aging population. It is estimated that 247,000 hip fractures occur yearly in the United States, with a majority occurring in the population over 45 years old [6]. The incidence of hip fracture is on the rise, partly due to the aging population. The cost of these fractures is also expected to rise from $\$ 7$ billion per year [6], to nearly $\$ 16$ billion per year by 2040 [7]. Each hip fracture is estimated to cost between $\$ 39,555$ and $\$ 40,600$ in the first year after surgery [8]. Hip fractures have the highest cost of any orthopaedic procedure after surgery, amounting to an extra $\$ 11,241$ per year in health costs. Due to increased life expectancy, worldwide by 2050 , it is projected that 6.26 million hip fractures will occur each year [9]. Hip fracture surgery is one of the most common orthopaedic surgeries, behind only knee arthroscopy, shoulder arthroscopy, removal of a support implant, and total knee replacement. Approximately half of the population 85 years old or older has a hip fracture. Hip fractures have a mortality rate of 21.9 percent within 1 year of surgery.

Revision surgery can be necessary following primary total hip replacement surgery, if complications occur. Also after a successful operation a new hip is generally required after 20 years. The reason for revision surgery being required can be due to incorrect stem placement in the primary surgery, which may in some cases result from lack of surgeon experience, which simulators may help to improve. The incidence of dislocation is between 2-6\% and even higher following revisions [10]. Other studies report up to 8\% dislocation [11]. There have been an increased number of hip revision surgeries recently associated with metal-metal prosthesis acetabular cups in hip prostheses which produce billions of submicrometer wear particles annually that can cause osteolysis and loosening of the components [12]. Another complication is impingement between the neck of the femoral implant and the rim of the acetabular component. Impingement can lead to advanced wear of the acetabulum rim resulting in polyethylene wear debris shown to accelerate loosening of implant bone interfaces. The most common cause of both impingement and dislocation is malposition of the acetabular component, which may be caused by lack of surgeon experience. Training simulators could specifically allow practice of this key skill. Simulating these key procedures could improve the skill of novice hip surgeons and reduce the risk of injury to patients.

\subsection{Advantages of virtual reality over conventional training}

A paradigm shift toward use of surgical training simulations is underway [13], [14]. The conventional masterapprentice learning model for surgical training of 'see one, do one, teach one' is inefficient with no guarantee of case mix. Due to orthopaedics being heavily dependent on technical skill, orthopaedic VR simulation holds great potential creating a heavy impact on improving surgical skill. The transition to VR simulation has only begun in the past twenty years, whereas cadaver training has been the gold standard for over 500 years.

Training with VR could be particularly useful for medical residents. Residency refers to a stage of graduate medical training, for a trainee who has received the title of 'physician,' usually a M.D., D.O., or MBBS, MBChB, BMed.

Residents trained with virtual reality perform surgery substantially faster, whereas residents with conventional training are slower, much more likely to cause injury, damage tissue or fail to progress the surgery, as demonstrated by a prospective, randomized, blinded study on the MIST-VR laparoscopic simulator [15]. Similar benefits of VR training were demonstrated in laparoscopic [16] and shoulder arthroscopy simulators [14].

An article dating back to 1986 on computer-aided orthopaedic surgery concluded that "real time operative rehearsal, precision surgical planning and execution, and interactive teaching programs will be widely used once the costs associated with this technology come within the reach of clinical and teaching budgets" [17].

Simulation is particularly attractive in the field of surgery because it avoids the use of patients for skills practice and ensures that trainees have had some practice before treating humans. Also simulation avoids need for cadavers or animals, which are currently the most realistic method of training. Surgical simulations break down the procedure into tasks, concentrating on chains of behaviour. The aim of surgical simulation is to improve the training of the surgeons of the future by providing a controlled, risk free environment where they can develop their operative and decision-making skills without any potential harm to patients. The idea is that they reach a certain level of skill before progressing to 'real life' operating theatre scenarios.

Virtual reality provides enhanced understanding of complex 3D bony structures and handling of instruments [18]. Haptic technology can provide tactile experience of the surgical procedure and can be further advanced when combined with patient specific MRI or CT data for automatic segmentation for use in a visual and haptic virtual environment [19].

Scoring and assessment can be incorporated into VR simulators with the ability to replay or review. This can provide an objective unbiased score. An orthopaedic curriculum was recently developed containing 4 bone training modules to 
assess and track progress in orthopaedic manual skills [20]. Modules include (1) cortical drilling, (2) drill trajectory, (3) oscillating saw, and (4) pedicle probing. These modules were tested on 15 orthopaedic surgery residents and results were promising [20].

Surgical procedures require the operator to understand the anatomy and develop their sense of touch for procedures. VR training simulators assist the development of visuospatial awareness of anatomy and 'feel' of the procedure by allowing practice prior to in-vivo procedures. This will enhance patient safety in addition to creating a safe and controlled environment in which to practice the procedure. The ability for simulators to assess skill level or analyse performance of practical skills has been demonstrated by several studies including [21]. Simulation is gaining popularity not only for the purpose of creating mock scenarios but also in learning psychomotor skills [22].

\subsection{Literature search methods}

A literature search was performed to find existing orthopaedic training simulators. The Medline (Pubmed) database was used for searches of medical subject headings (MeSH) terms. Keyword searches were carried out additionally using alternative databases including searches from ACM Digital Library, IEEE Xplore, ASME Digital Collection, IEEE/IET Google Scholar and Electronic Library (IEL) which produced further relevant titles. Patent searches were conducted to identify existing intellectual property protection via the worldwide patent database using the European patent office (EPO). Searches for related hip surgery simulators used systematic keywords combining one word from List A with one word from List B, as shown in Table 1 .

\begin{tabular}{|l|l|}
\hline LIST A & LIST B \\
\hline Hip Replacement & Simulator \\
\hline Hip surgery & Simulation \\
\hline Hip Arthroplasty & Training \\
\hline Hip Arthroscopy & Preoperative model system \\
\hline Hip Resurfacing & Preoperative planning \\
\hline Orthopaedic & Virtual \\
\hline Orthopedic & Virtual reality \\
\hline Total Hip & Commercial simulator \\
\hline Prosthesis & Computer simulator \\
\hline Prostheses & VR \\
\hline
\end{tabular}

Table 1. Lists of the keyword sets used during literature and worldwide patent searching.

Fig. 1 shows the annual distribution of literature for virtual reality simulators in PubMed. Most papers were published after 1995 and publications have increased almost every year since.

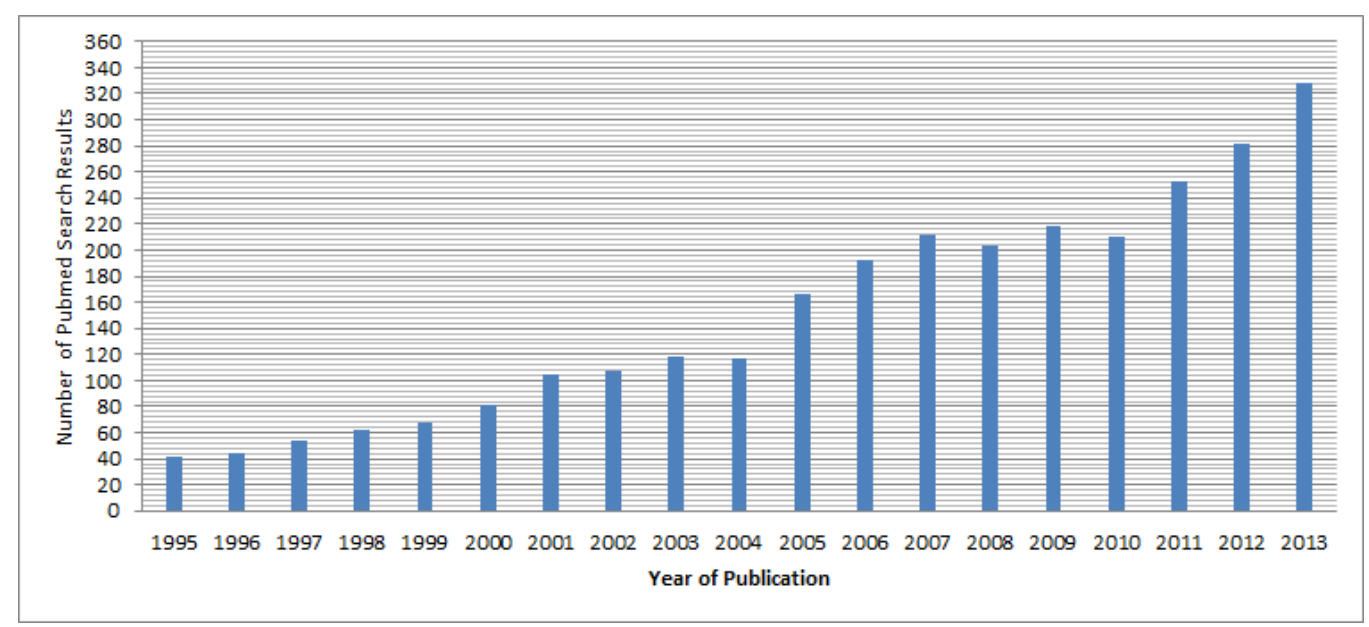

Fig. 1. Pubmed search results by year. The majority of computer simulation and virtual reality literature was published after 1995 .

\section{Orthopaedic training simulators}


This section aims to outline and classify the existing orthopaedic training simulators, which are outlined below in four categories: (i) elective hip surgery simulators, (ii) hip trauma and fracture fixation simulators, (iii) knee procedure training simulators and (iv) other orthopaedic procedures including pelvis, spine and shoulder surgery.

\subsection{Elective total hip replacement and resurfacing simulators}

This section covers elective procedures which are surgeries scheduled in advance, as they do not involve a medical emergency. Total hip replacement is usually elective as the patient plans to have the procedure in advance. Trauma surgery which is completed urgently following an accident is covered in section 2.2.

A set of biomedical software tools has been combined into the Mimics innovation suite ${ }^{1}$, [23] (Materialise, Leuven, Belgium) allowing medical image data from patients to be converted into 3D models of the patient's skeletal structures (Fig. 2a). These bone models can then be manipulated virtually to simulate osteotomies by cutting bone, repositioning parts, placing implants and bone plates. Various surgical approaches can be tried before selecting the optimal approach.

There are various open source software platforms designed to convert Medical images into 3D models. Medical Image Processing and Visualization (MIPAV) [24] is an open source tool to apply surface representation on a DICOM dataset. The Medical Imaging Interaction Toolkit Workbench (MITK) [25], is a tool for DICOM import, segmentation, mesh generation and volume visualization. Also 3DSlicer [26] is an open-source software tool for converting DICOM to STL. More professional standard options are also available including Simpleware [27] and 3D Doctor [28]. Some professional products such as Osirix [29] comes in free versions for research but is paid for in versions for clinical work with Food and Drug Administration (FDA) approval.

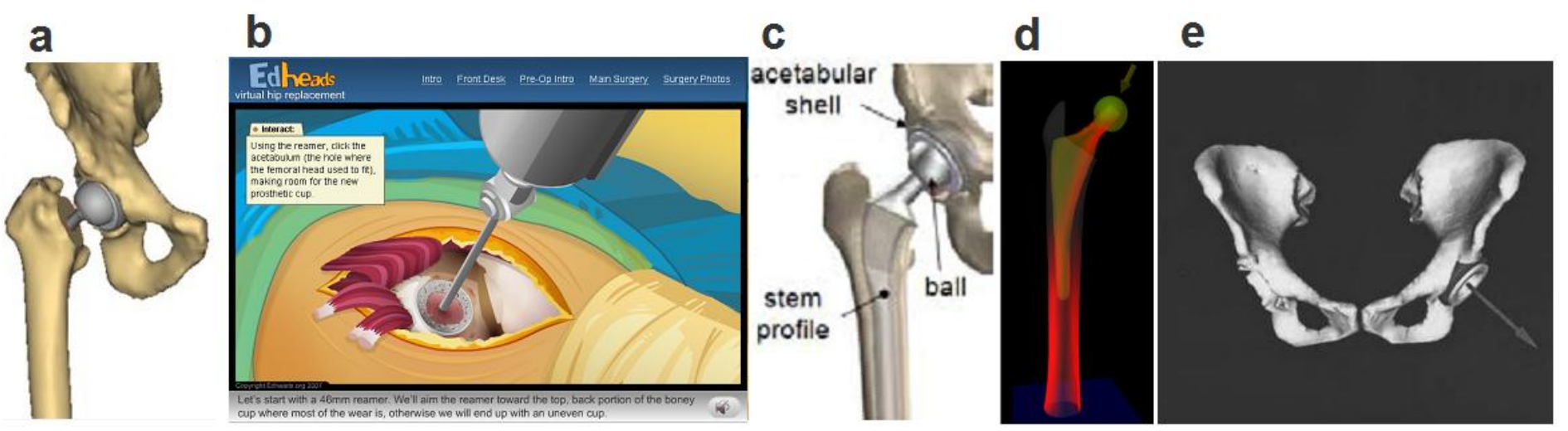

Fig. 2. a) Mimics innovation suite [23] (Materialise, Belgium). b) Edheads hip replacement and resurfacing educational games [30], [31] c) 3D preoperative hip implant planning tool Jun \& Park, 2011 [33] d) 3D pre-operative hip implant planning simulation tool by Dick et al. [34] e) HipNav developed at Carnegie Mellon University by Digioia et al. [35].

Two interactive games for total hip replacement and resurfacing have been designed by Edheads ${ }^{2,3}$ for children's education (Fig. 2b) [30], [31]. The hip procedures are described including dislocation, reaming, acetabular cup placement, stem insertion and completion. Two different patients are included with various age, weight and height. The procedural steps of hip surgery can be learnt and knowledge is assessed by quiz questions. No physical skill is required from the user to complete the game, so this does not allow learning of the physical feel of the procedure. The games were produced in 2007 by Edheads, a non-profit education resource organisation [30], [31]. The research was completed by University of Wisconsin, Madison at the Department of Orthopedics and Rehabilitation. The game was aimed at children aged 7-12 as an educational tool for individuals or group work. The games take around 15 minutes to complete, targeting various curriculum points in science and technology. The games are also available as Android apps for portable devices.

Simulations of the pre-operative stage of THR were developed by Sato et al. [32]. This system allows planning for the optimal selection of parameters such as cup size, position and orientation of stem. These are determined through surgical planning that includes range of motion (ROM) simulation and limb length adjustment.

A 3D pre-operative hip implant planning tool by Jun \& Park [33] involves patient-specific prostheses for a particular patient by investigating the 3D anatomy of the hip (Fig. 2c). Five steps of the hip procedure were modelled; (1) 3D reconstruction of the hip from CT scans. (2) Design of a hip prosthesis for individual. (3) Virtual femoral head resection and implantation. (4) Prosthesis evaluation. (5) Generation of 3D surgical parameters.

\footnotetext{
${ }^{1}$ Materialise Mimics Innovation Suite. <http://biomedical.materialise.com/mis $>$

${ }^{2}$ EdHeads Hip Replacement Online Game (2007). <http://www.edheads.org/activities/hip/>

${ }^{3}$ EdHeads Hip Resurfacing Online Game (2007). <http://www.edheads.org/activities/hip2/>
} 
A computer-based 3D pre-operative hip implant planning simulation tool by Dick et al. [34] is based on patientspecific CT scan finite element data (Fig. 2d). The system aims to simulate the mechanical response of a patient-specific bone to a load that is applied to the implant, and to identify which available implant design and size results in the most physiological stress distribution.

HipNav was developed in 1995 at Carnegie Mellon University [35], [36]. Seven years later in 2002 HipNav was still the most comprehensive total hip replacement planner [37]. The 3D patient anatomy can be generated from CT or MRI scans. Pre-operative 3D reconstruction simulation software allows the surgeon to specify the position of the acetabular component within the pelvis based upon pre-operative CT images. HipNav includes kinematic hip joint models and tools for predicting femoral range of motion, bone motion, and optimal alignment based on implant placement (Fig. 2e). Feedback provided by the simulator can aid the surgeon in determining optimal, patient specific acetabular implant placement. For use in-vivo, the data and preoperative plans are transferred to a computer station in the operating room for interactive in-vivo surgical navigation. HipNav was the first hip navigation concept to be used clinically [38].

a

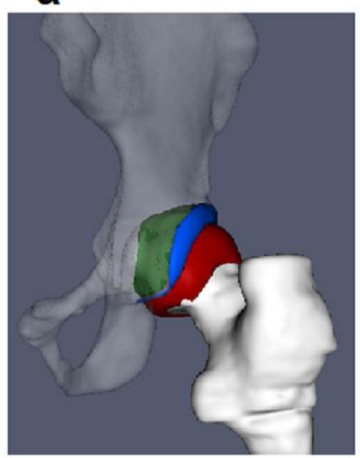

b

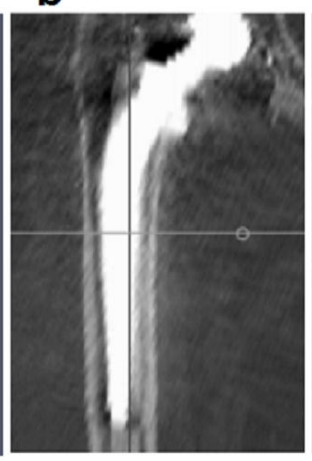

C

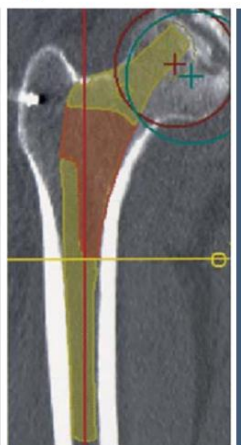

d

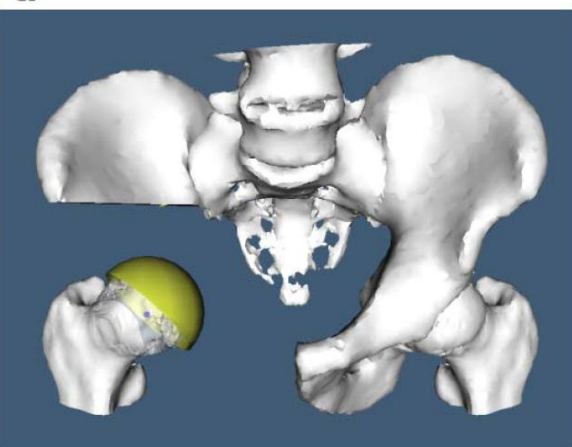

e

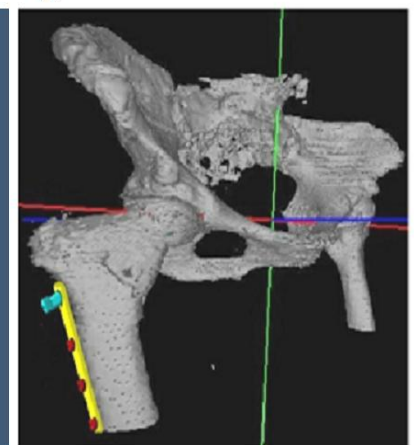

Fig. 3. a) Hip musculoskeletal disorder simulation by Assassi et al. [39]. b) Revision total hip replacement (RTHR) surgeries simulator by Taylor et al. 2009 [41]. c) Orthodoc - a pre-operative planning tool for primary total hip replacement by Nishihara et al. [43]. d) Virtops endoprosthetic reconstruction of the hip joint by Handels [45]. e) A volume based haptic surgical hip drilling simulator introduced by Tsai et al. (2007) [48].

A musculoskeletal disorder simulation by Assassi et al. [39] models hip osteoarthritis and abnormal femoroacetabular movement (Fig. 3a). An optical tracking system is used in combination with MRI. The MRI images are used to generate anatomical simulation of the hip joint. This results in a fast functional joint model, used to achieve accurate and realistic soft tissues and cartilage deformations.

A manikin based hip arthroscopy bench-top simulator was developed by Sawbones ${ }^{4}$ [47] (Europe). A study by Pollard et al., [40] demonstrated this simulator can aid trainee learning with objective improvement. Trainees are likely to benefit from simulator training to both lateral and suppine orientation and basic competence. The Sawbones simulator is solely a bench-top simulator but like other manikin simulators this does not make use of VR technologies.

A computer driven system has been proposed to assist surgeons in revision total hip replacement (RTHR) surgeries Taylor et al. [41] (Fig. 3b). The simulator aims to achieve (1) reduction of cement removal labor and time, (2) elimination of cortical wall penetration and femur fracture, (3) improved positioning and fit of new implant (4) precise, high-quality canal milling (5) reduction of bone sacrificed to fit the new implant.

The Robodoc is a computer-integrated surgical robot for cementless total hip replacements (Fig. 3c). It is safe and successful, designed to reduce human error using a five axis robotic arm with milling device. The first human hip surgery was performed by Robodoc in 1992 by Pransky et al. [42]. The system contains Orthodoc, a pre-operative planning workstation, showing a 3D image of the bone [43]. The Orthodoc images are based on CT scans and a vast array of possible implants are modelled [44]. Robodoc was created by a US company, Integrated Surgical Systems (ISS) in 1990 and received FDA approval 1997.

The hip simulator Virtops (Virtual Operation Planning in Orthopaedic Surgery) software system was produced by Handels et al [45] for virtual pre-operative planning and simulation of hip operations. Polarised glasses are included to provide stereoscopic visualisation. A spaceball provides six degrees of freedom as an input device. The system is applied to simulate the endoprosthetic reconstruction of the hip joint with hemipelvic replacement, and supports the individual design of anatomically adaptable, modular prostheses in bone tumor surgery [46] (Fig. 3d).

In summary, there are several pre-operative planning tools available for elective hip surgery, however there are not many simulators aimed at training. In order to provide comparison between the hip elective surgery simulators, Table 2 shows various features of each simulator.

\footnotetext{
${ }^{4}$ Sawbones Mannikin based hip arthrosopy bench-top simulator. 〈http://www.sawbones.com/Catalog/Orthopaedic\%20Models/Hip/9077-9>
} 


\begin{tabular}{|l|l|l|l|l|l|l|l|l|l|}
\hline & & & & & & \\
\end{tabular}

Table 2. Hip elective total replacement or resurfacing simulators comparative assessment.

\subsection{Hip trauma and fracture fixation simulators}

This section covers trauma procedures, which is surgery completed at short notice, often due to an accident. Hip fracture repair is usually a trauma procedure as they are required urgently.

Many previous papers have referred to SensAble Phantom haptic devices, used in several simulators. It is worth noting that SensAble has been taken over by Geomagic, a 3D systems division. The SensAble Phantom Omni device is now known as Geomagic Touch [84]. Phantom Desktop is now known as Geomagic Touch X [49]. The Sensable Phantom Premium is now Geomagic Phantom Premium [83], which comes in three models: 1.0, 1.5 and 1.5 high torque, and 3.0.

A volume based surgical simulator with haptic functions to simulate the hip drilling process of screw and plate surgery for positioning the hip trochanter fracture was introduced by Tsai et al. [48] (Fig. 3e). The haptic functions compute drilling forces and torques based on metal removing theorem. Prediction for the drilling process can be obtained to provide surgery training and rehearsal. It is not clear whether vibration sensation is included, however if it is, due to the $1 \mathrm{KHz}$ technology limitations of response frequency from a Geomagic Touch $\mathrm{X}^{5}$ [49] haptic device, the higher frequency vibrational drilling cues may not be exactly replicated in the simulator. Also the simulator may not account for the weight of a surgical drill in the hand of the trainee.

A drilling simulator using a Geomagic Touch X [49] haptic device was developed by Vankipuram et al. [50] to generate realistic drilling haptics. The software allows horizontal drilling through the femoral body with accuracy analysed with respect to virtually shown targets (Fig. 4a). The study shows differentiation of skill between novices, residents, and experts, as experienced subjects were more accurate in drilling.

\footnotetext{
${ }^{5}$ Geomagic Touch X haptic device. 〈http://www.geomagic.com/en/products/phantom-desktop/overview〉
} 

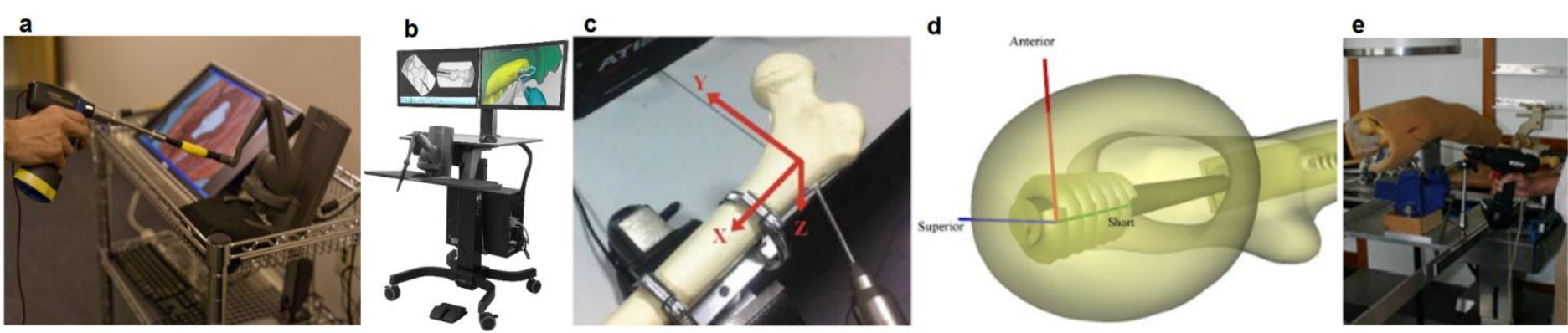

Fig. 4. a) Orthopaedic haptic drilling simulator by Vankipuram et al. [50]. B) Swemac Traumavision (STV) Orthopaedic Simulator [51]. c) Haptic Orthopaedic Training (HOOT) Drilling training simulator [52], by Barrow et al. [53] Imperial College London 2012. d) BoneDoc virtual reality simulator for hip fracture screw and plate fixation by Blyth et al. 2009 [57]. E) Computer-Assisted Orthopedic Surgery system (CAOS) by Rambani et al. 2014 [2].

The TraumaVision fractured femur orthopaedic simulator ${ }^{6}$ with simulated fluoroscopy [96] (Fig. 4b) was produced by Swemac, Melerit and Simulution Inc (Burnsville, MN) [51]. The TraumaVision simulator has been tested in a study with 15 residents simulating a drill placing the guide pin. The trial found residents with more experience had differences in number of attempts at surgery and time taken in fluoroscopy. This shows the simulator is sensitive enough to evaluate differences in surgical technique between junior and senior residents. The Traumavision simulator [96] uses a Geomagic Touch X haptic device [49].

The Haptic Orthopaedic Training (HOOT) ${ }^{7}$ simulator [52] (Fig. 4c) allows training for hip surgery drilling, and guide wire placement in dynamic hip screw operations, developed at Imperial College London in 2012. Dynamic hip screw (DHS) is a common operation whereby a DHS is inserted into the femur to correct particular kinds of hip fracture. A key step in DHS surgery is the initial pilot hole drilled using a long flexible drill bit through the outside edge of the femur and up into the femoral head.

The BoneDoc dynamic hip screw (DHS) simulator ${ }^{8}$ [97] (Fig. 4d) is a virtual reality simulator for screw and plate fixation of hip fractures which runs on a standard PC, developed by Blyth et al. [54-56]. The authors aimed for the simulator to tell the difference between users with differing operative experience levels. Assessment and scoring has been included in several categories including locking screws, screw, guide wire, and time. No somatosensory/haptic/physical aspects are included, a mouse is used for simulator input, allowing software to run on a standard PC. BoneDoc was tested by 31 fifth year trainees, showing that the simulator improved key understanding of the surgical procedure [57]. Otago Innovation Limited was involved to commercialise the BoneDoc simulator developed at University of Otago [97].

A simulated computer-navigated training system to perform lumbar spine pedicle screw insertion and dynamic hip screw fracture fixation was developed by Rambani et al., 2014 [2] (Fig. 4e). The Computer-Assisted Orthopedic Surgery system (CAOS) was developed by the Simulation and Visualization Research Group, Rambani et al in 2013 [58] of which earlier versions have been in use since 1992. This uses the Polaris optical tracking system by Northern Digital Inc. ${ }^{9}$ [66] to track motion of the surgical tools. Real patient computed tomography scans are used to produce the fluoroscopic images of the lumbar spine. Simulator validation showed simulator training led to statistically significant improvement in time taken, fixation accuracy, and number of exposures [2].

A hip fracture surgery simulator developed by Linköping University ${ }^{10}$ in 2012 [59] using a Geomagic Touch X haptic device [49] connected to surgical tools for tactile feedback [61]. Patient-specific virtual models of the femur and pelvis were automatically segmented from actual patient computer tomography (CT) data. Polygon model included 3D graphical models of the data, simulated fluoroscopy images and sound reproduction. The surgeon can practice positioning of nail implants in the femoral bone. For pre-operative planning it is necessary to obtain patient-specific models rapidly which required automatic segmentation. To accomplish this, a non-rigid registration algorithm, the Morphon method, has been employed by Wrangsjö et al., 2005 [60] and Pettersson et al., 2005 [62,63]. The method uses the general registration technique, where a prototype image/volume, is iteratively deformed to fit the corresponding structure in the target image/volume. The implemented haptic interaction takes into account several different aspects of bone drilling and effectively renders the interplay between the elongated body of the drill and the drill hole and its surrounding bones. It allows for the use of several different approaches to use the sense of touch and the guiding feedback from bones with

\footnotetext{
${ }^{6}$ Swemac Traumavision 〈http://www.swemac.com/simulators/traumavision>

${ }^{7}$ HOOT Simulator by Imperial College London (2014) 〈http://www1.imperial.ac.uk/simms/research/procedure_modelling simulation/hoot $>$

${ }^{8}$ BoneDoc, About the BoneDoc Simulator. <http://bonedoc.org/about.html $>$

${ }^{9}$ Northern Digital Inc., Polaris optical tracking system <http://www.ndigital.com/medical/products/polaris-family $>$

${ }^{10}$ Linköping University, Sweden, Haptic Simulation of Hip Fracture Surgery, (2012) < http://www.imt.liu.se/mi/Research/simulator $>$
} 
varying density to find the optimal path for the pilot drill. This presents to the user, in combination with the fluoroscope simulation, realistic issues and means for performing a correct procedure.

Computer algorithms were developed for assessing $\mathrm{x}$-ray images for a pre-operative planning system for hip fracture surgery by Tseng et al., 2011 [64].

A fluoroscopic-based wire navigation training simulator for hip fractures demonstrated the detection of quantifiable differences between undergraduate students, novices, and experienced surgeons on a simulator by Johns, 2014 [1]. The system uses a real drill and guide wire instead of a haptic device. Using a real drill incorporates realistic weight, vibration, and sound. An artificial femur ensures realistic wire advancement force and torque. To synchronize real-world drill movements with the virtual graphics component this simulator uses a wireless electromagnetic motion tracking system using orthogonal coils to receive transmitted electromagnet waves from the Ascension 3D Guidance trakSTAR ${ }^{\text {TM }}$ 6$\mathrm{DOF}^{11}$ [65]. Activating the drill generates electromagnetic noise disrupting accuracy. The average overall spatial error of sensors is $3.57 \mathrm{~mm}$. The simulator displays virtually generated fluoroscopy. Model bones are used inside a foam tube to obstruct direct view. Each time the simulator is used, the bones get drilled into which causes damage. Replacement bones are a reoccurring cost; however the bones could be repaired with glue to enable several simulations using the same bone. The virtual 3D bone model was generated from a laser scan of the physical model to ensure correlation. Trials with orthopaedic surgeons indicate that the simulator objectively measures the surgical skill, showing that this augmented reality approach provides a valuable training and assessment tool in wire navigation of the proximal femur.

In summary, there are a number of existing VR training simulators for hip fracture repair trauma. There are more training simulators for trauma hip surgery than for elective hip replacement surgery. In order to provide comparison between hip trauma simulators, Table 3 lists the simulators with their various features.

\begin{tabular}{|c|c|c|c|c|c|c|c|c|c|}
\hline & 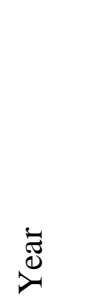 & 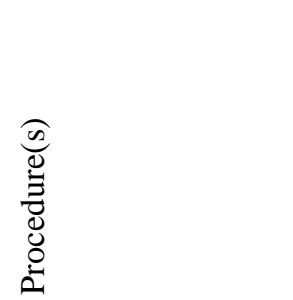 & 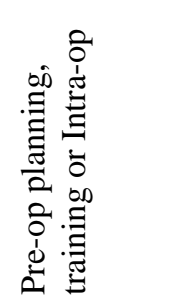 & 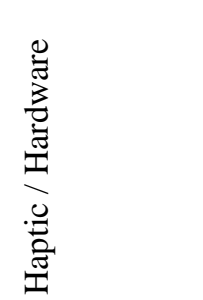 & 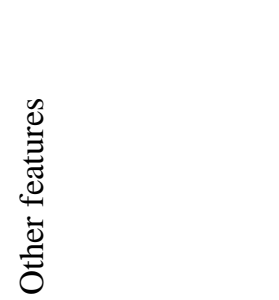 & 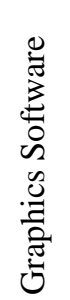 & 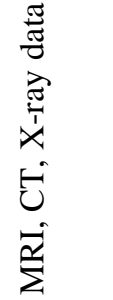 & 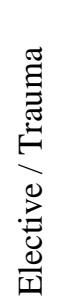 & 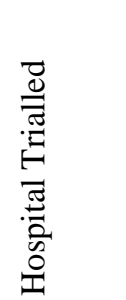 \\
\hline $\begin{array}{l}\text { Linköping } \\
\text { University [59] }\end{array}$ & 2012 & $\begin{array}{l}\text { Hip fracture } \\
\text { surgery }\end{array}$ & Pre-op & $\begin{array}{l}\text { Geomagic } \\
\text { Touch X } \\
\text { [49] }\end{array}$ & $\begin{array}{l}\text { Patient-specific } \\
\text { segmentation }\end{array}$ & $3 \mathrm{D}$ & $\mathrm{CT}$ & $\mathrm{T}$ & No \\
\hline $\begin{array}{l}\text { HOOT Imperial } \\
\text { College London } \\
\text { [52] }\end{array}$ & 2012 & $\begin{array}{l}\text { Dynamic hip screw } \\
\text { (DHS) }\end{array}$ & Training & $\begin{array}{l}\text { W5D Entact } \\
\text { Robotics }\end{array}$ & $\begin{array}{l}\text { Rotational and } \\
\text { linear haptics }\end{array}$ & $3 \mathrm{D}$ & Xray & $\mathrm{T}$ & $\begin{array}{l}\text { Pilot is } \\
\text { planned }\end{array}$ \\
\hline $\begin{array}{l}\text { BoneDoc. Blyth } \\
\text { et al. [54] }\end{array}$ & 2007 & $\begin{array}{l}\text { Dynamic hip screw } \\
\text { (DHS) }\end{array}$ & $\begin{array}{l}\text { Training + } \\
\text { Assessment }\end{array}$ & $\begin{array}{l}\text { Mouse } \\
\text { Non-haptic }\end{array}$ & $\begin{array}{l}\text { Assessment + } \\
\text { scoring }\end{array}$ & $\begin{array}{l}\mathrm{DD} \\
\mathrm{VR}\end{array}$ & No & $\mathrm{T}$ & $\begin{array}{l}31 \\
\text { trainees }\end{array}$ \\
\hline Tsai et al. [48] & 2007 & $\begin{array}{l}\text { Hip fracture, DHS } \\
\text { and plate surgery. }\end{array}$ & $\begin{array}{l}\text { Training + } \\
\text { rehearsal }\end{array}$ & $\begin{array}{l}\text { Geomagic } \\
\text { Touch X } \\
{[49]}\end{array}$ & $\begin{array}{l}\text { Haptic force and } \\
\text { torque }\end{array}$ & $3 \mathrm{D}$ & $\begin{array}{l}\mathrm{CT}+ \\
\text { MRI }\end{array}$ & $\mathrm{T}$ & No \\
\hline Tseng et al. [64] & 2011 & $\begin{array}{l}\text { Hip fracture } \\
\text { surgery }\end{array}$ & Pre-op & No & $\begin{array}{l}\text { Virtual reduction } \\
\text { of femur bones }\end{array}$ & $3 \mathrm{D}$ & Xray & $\mathrm{T}$ & $\begin{array}{l}\text { Two } \\
\text { cases }\end{array}$ \\
\hline $\begin{array}{l}\text { Vankipuram et } \\
\text { al. [50] }\end{array}$ & 2010 & $\begin{array}{l}\text { Hip fracture } \\
\text { drilling simulator }\end{array}$ & $\begin{array}{l}\text { Training + } \\
\text { Assessment }\end{array}$ & $\begin{array}{l}\text { Geomagic } \\
\text { Touch X } \\
\text { [49] 3DOF }\end{array}$ & $\begin{array}{l}\text { Assessment. } \\
\text { Synthes® surgical } \\
\text { drill }\end{array}$ & $3 \mathrm{D}$ & $\begin{array}{l}\mathrm{CT}+ \\
\text { MRI }\end{array}$ & $\mathrm{T}$ & $\begin{array}{l}6 \text { expert } \\
21 \\
\text { novices }\end{array}$ \\
\hline $\begin{array}{l}\text { Traumavision } \\
\text { Swemac [96] }\end{array}$ & 2011 & $\begin{array}{l}\text { Drilling \& guide } \\
\text { pin placement }\end{array}$ & $\begin{array}{l}\text { Training + } \\
\text { Assessment }\end{array}$ & $\begin{array}{l}\text { Geomagic } \\
\text { Touch X } \\
{[49]}\end{array}$ & $\begin{array}{l}\text { Assessment. Also } \\
\text { spinal surgery }\end{array}$ & $3 \mathrm{D}$ & $\begin{array}{l}\text { Fluoro } \\
\text { scopy }\end{array}$ & $\mathrm{T}$ & No \\
\hline $\begin{array}{l}\text { Johns Physical } \\
\text { bones [1] }\end{array}$ & 2014 & $\begin{array}{l}\text { Hip fractures wire } \\
\text { navigation }\end{array}$ & $\begin{array}{l}\text { Training + } \\
\text { Assessment }\end{array}$ & $\begin{array}{l}\text { Ascension } \\
\text { trakSTARTM } \\
\text { 6-DOF [65] }\end{array}$ & Real drill included & $3 \mathrm{D}$ & No & $\mathrm{T}$ & $\begin{array}{l}\text { Ortho } \\
\text { surgeon } \\
\text { trial }\end{array}$ \\
\hline $\begin{array}{l}\text { CAOS. Rambani } \\
\text { et al. [58] }\end{array}$ & 2013 & $\begin{array}{l}\text { DHS, hip fracture } \\
\text { fixation }\end{array}$ & $\begin{array}{l}\text { Training + } \\
\text { Assessment }\end{array}$ & $\begin{array}{l}\text { Polaris } \\
\text { optical } \\
\text { tracking } \\
{[66]}\end{array}$ & Assessment & $3 \mathrm{D}$ & CT & $\mathrm{T}$ & $\begin{array}{l}12 \\
\text { senior } \\
\text { ortho }\end{array}$ \\
\hline
\end{tabular}

${ }^{11}$ Ascension, 3D Guidance trakSTAR TM 6-DOF <http://www.ascension-tech.com/products/trakstar-drivebay > 
Table 3. Hip fracture and hip trauma surgery simulators comparative assessment.

\subsection{Knee and other orthopaedic procedure training simulators}

This section covers training simulators for knee and other orthopaedic procedures which use similar techniques to hip replacement simulators.

A system was developed by Jun et al. 2012 [67] to simulate Total Knee Replacement (TKR) surgery based on 3D knee models reconstructed from patient Computed Tomography (CT) scans (Fig. 5a).

Knee arthroscopy surgical trainer (KAST) was developed by American Association of Orthopaedic Surgeons task force (Fig. 5b). KAST allows users to virtually go through the motions of a knee arthroscopy including the haptic feedback that allows the user to know if they're hitting cartilage or a tendon [68]. The core hardware is a pair of Geomagic Touch X haptic devices [49], two monitors and proprietary software based on the visible human project. KAST is already in use in several orthopaedic residency programs.
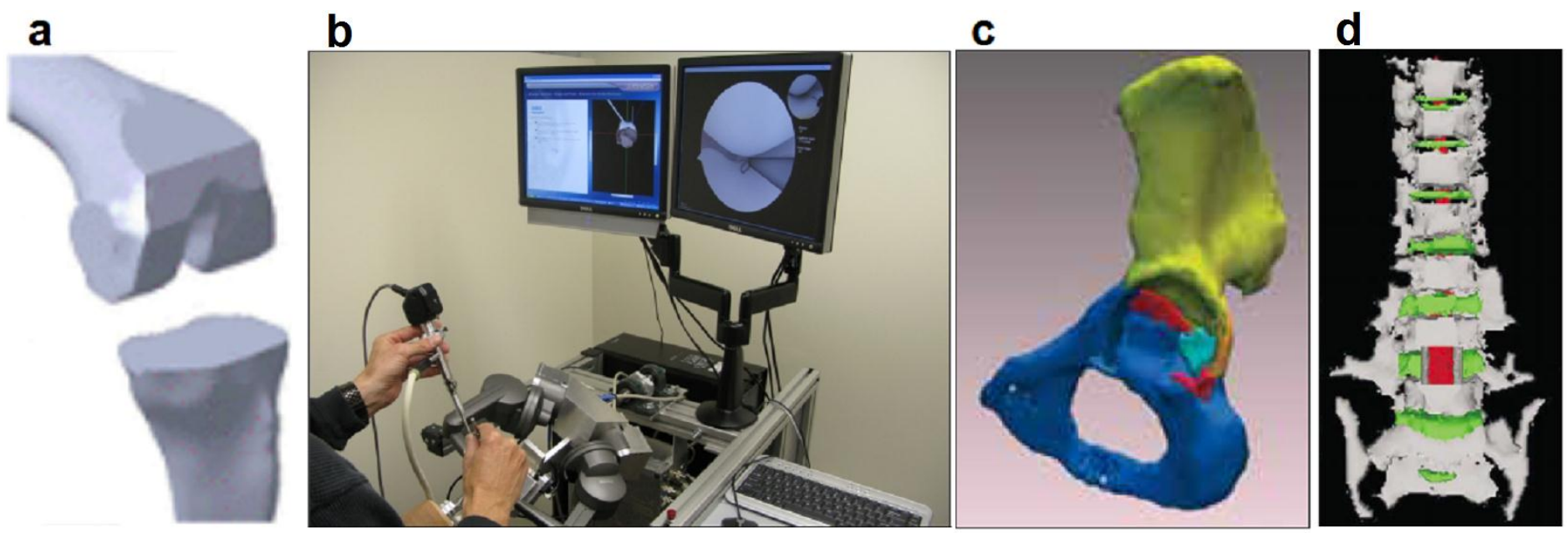

Fig. 5. a) Total Knee Replacement simulator by Jun et al. 2012 [67]. b) acetabular surgery pre-operative tool by Cimerman \& Kristan (2007) [75]. c) Knee arthroscopy surgical trainer (KAST) American Association of Orthopaedic Surgeons [68]. d) Orthopaedic surgery simulator by Tsai et al., (2001) [76].

A knee arthroscopic surgery simulator was constructed using a tailor made haptic force feedback device by Heng et al., 2004 [69]. The device allows 30 degree bending at the tip of the arthroscope providing for Pitch, Yaw, and Insertion which provides more degrees of freedom than commercially available haptic devices.

The virtual reality arthroscopic knee simulator (VR-AKS) has been developed by Mabrey et al. in 1999 [70] with support from the American Academy of Orthopaedic Surgeons (AAOS). Their system adopts a volumetric representation for anatomic structure and uses two Geomagic Touch ${ }^{12}$ [84] haptic feedback devices. However, due to the hardware limitation of the Geomagic Touch [84], the system can only impose positional Force which is limited compared to in-vivo forces.

McCarthy et al. developed a cost-effective VR simulator in 2006 [71], the Sheffield Knee Arthroscopy Training System (SKATS), using passive feedback from physical bones. They reported that it could differentiate between expert and novice surgeons.

A high force haptic system for knee arthroscopy training with four degree of freedom haptic system for virtual reality knee arthroscopy training. The compact device named OrthoForce was developed by Zivanovic et al. in 2006 [72].

The Simbionix arthro mentor is a commercial simulator designed for knee arthroscopy [106]. A pair of Geomagic Touch [84] haptic devices mimic surgical tools as well as generating haptic feedback. A virtually generated endoscopic image with surgical instruments is displayed to the trainee. The arthro mentor simulator was subject of a validity trial with 26 physicians to test reliability and validity [107]. Statistically significant differences in time and score were identified within 4 medical procedures between 13 novices and 13 experts.

The VirtaMed ArthroS ${ }^{\mathrm{TM}}$ is a knee and shoulder arthroscopy simulator [108]. It supports complication training, without risk to patients. Instruments include probe, grasper, punch or motorized shaver and haptic feedback is provided.

${ }^{12}$ Geomagic (2015) Touch Haptic Device. 〈http://www.geomagic.com/en/products/phantom-omni/overview〉 
Haptic minimally invasive hybrid virtual simulation solutions for arthroscopic knee procedures have been proposed [109]. The Geomagic Touch [84] haptic device was modified for MIS simulation, including incision of the arthroscopic camera, positioning of the instrument in front of camera and using scissors and graspers.

The commercial Simendo arthroscopy trainer [103] is used to certify laparoscopic skills and provides fundamental training such as whole knee joint examination and meniscus probing.

In summary, there are a number of existing knee replacement VR training simulators. In order to provide comparison between the knee surgery simulators, Tables 4 lists the simulators with their various features.

\begin{tabular}{|c|c|c|c|c|c|c|c|c|c|}
\hline & $\underset{\circlearrowright}{\circlearrowright}$ & 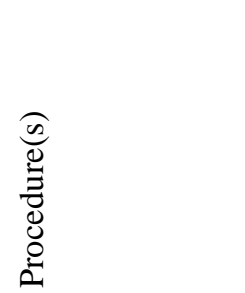 & 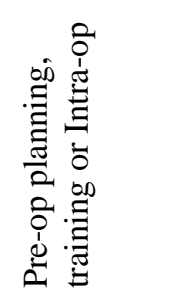 & 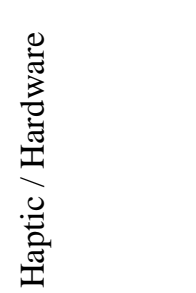 & 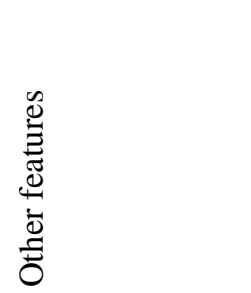 & 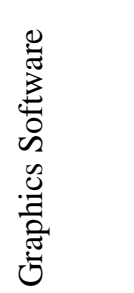 & 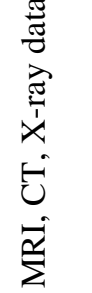 & 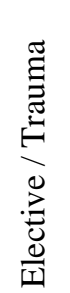 & 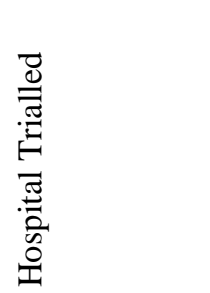 \\
\hline Jun et al. [67] & 2012 & $\begin{array}{l}\text { Total knee } \\
\text { replacement }\end{array}$ & Training & $\begin{array}{l}\text { Physical } \\
\text { knee model }\end{array}$ & $\begin{array}{l}\text { Custom fit } \\
\text { implants }\end{array}$ & $3 \mathrm{D}$ & $\mathrm{CT}$ & $\bar{E}$ & No \\
\hline Heng et al. [69] & 2004 & $\begin{array}{l}\text { Knee } \\
\text { arthroscopy }\end{array}$ & Training & $\begin{array}{l}\text { Tailor made } \\
\text { haptic tool }\end{array}$ & $\begin{array}{l}\text { Soft tissue } \\
\text { deformation }\end{array}$ & $3 \mathrm{D}$ & $\begin{array}{l}\text { CT } \\
\text { MRI }\end{array}$ & $\mathrm{E}$ & $\begin{array}{l}\text { Medical } \\
\text { Students }\end{array}$ \\
\hline $\begin{array}{l}\text { (VR-AKS). } \\
\text { Mabrey et al. } \\
{[70]}\end{array}$ & 1999 & $\begin{array}{l}\text { Knee } \\
\text { arthroscopy. }\end{array}$ & Training & $\begin{array}{l}\text { 2xGeomagic } \\
\text { Touch [84] }\end{array}$ & $\begin{array}{l}\text { Physical knee } \\
\text { model }\end{array}$ & $3 \mathrm{D}$ & No & $\mathrm{E}$ & No \\
\hline AAOS KAST & 2010 & $\begin{array}{l}\text { Knee } \\
\text { arthroscopy }\end{array}$ & Training & $\begin{array}{l}2 \text { xGeomagic } \\
\text { Touch X } \\
{[49]}\end{array}$ & $\begin{array}{l}\text { Limitless virtual } \\
\text { patients }\end{array}$ & $3 \mathrm{D}$ & No & $\mathrm{E}$ & $\begin{array}{l}\text { Orthopaedic } \\
\text { Residency }\end{array}$ \\
\hline $\begin{array}{l}\text { McCarthy et al. } \\
\text { VR (SKATS) } \\
\text { [71] }\end{array}$ & 2006 & $\begin{array}{l}\text { Knee } \\
\text { Arthroscopy }\end{array}$ & Training & $\begin{array}{l}\text { Passive } \\
\text { resistance. }\end{array}$ & $\begin{array}{l}\text { Assessment and } \\
\text { scoring }\end{array}$ & Camera & No & $E$ & 26 surgeons \\
\hline $\begin{array}{l}\text { OrthoForce, } \\
\text { Zivanovic et al. } \\
{[72]}\end{array}$ & 2006 & $\begin{array}{l}\text { Knee } \\
\text { Arthroscopy }\end{array}$ & Training & $\begin{array}{l}\text { High Force } \\
\text { custom tool }\end{array}$ & $\begin{array}{l}\text { Compact. 4- } \\
\text { DOF device }\end{array}$ & $3 \mathrm{D}$ & No & E & No \\
\hline $\begin{array}{l}\text { Simbionix } \\
\text { Arthro Mentor } \\
{[106]}\end{array}$ & 2012 & $\begin{array}{l}\text { Knee, shoulder } \\
\text { and hip }\end{array}$ & Training & $\begin{array}{l}\text { 2xGeomagic } \\
\text { Touch [84] }\end{array}$ & $\begin{array}{l}\text { Physical knee } \\
\text { model with } \\
\text { curriculum. }\end{array}$ & $3 \mathrm{D}$ & No & $\mathrm{E}$ & $\begin{array}{l}26 \text { physicians } \\
{[107]}\end{array}$ \\
\hline $\begin{array}{l}\text { VirtaMed } \\
\text { ArthroS }^{\mathrm{TM}} \\
{[108]}\end{array}$ & 2013 & $\begin{array}{l}\text { Knee and } \\
\text { Shoulder } \\
\text { Arthroscopy }\end{array}$ & $\begin{array}{l}\text { Training } \\
\text { and } \\
\text { feedback }\end{array}$ & $\begin{array}{l}\text { Original } \\
\text { tools }\end{array}$ & $\begin{array}{l}50+\text { virtual } \\
\text { patients, } \\
\text { complication } \\
\text { training }\end{array}$ & $3 \mathrm{D}$ & No & $\mathrm{E}$ & No \\
\hline $\begin{array}{l}\text { Simendo } \\
\text { arthroscopy } \\
\text { trainer [103] }\end{array}$ & 2006 & $\begin{array}{l}\text { Knee } \\
\text { Arthroscopy }\end{array}$ & $\begin{array}{l}\text { Training } \\
\text { and } \\
\text { assessment }\end{array}$ & $\begin{array}{l}\text { Custom } \\
\text { haptic tools }\end{array}$ & $\begin{array}{l}\text { Assessment of } \\
\text { skill }\end{array}$ & $3 \mathrm{D}$ & No & $\mathrm{E}$ & $\begin{array}{l}\text { Questionnaire } \\
\text { with } 75 \\
\text { participants } \\
{[104]}\end{array}$ \\
\hline
\end{tabular}

Table 4. Knee orthopaedic surgery simulators

The virtual orthopaedic surgery training simulator, developed by Sourin \& Sourina in 2000 [73,74] implements tools allowing surgeons to learn how to fix fractured bones and perform preoperative planning without wasting expensive synthetic bones. The software works on common PCs and simulates surgical techniques, implants, and tools. Virtual input/output devices can be used to increase realism and provide immersion. The software also simulates internal operations for some bone diseases, like slipped capital femoral epiphyses, ankle arthrodeses, sacroiliac joint disruptions, subtalar arthrodesis. No experimental studies or validation procedures were done.

A computer model for pre-operative planning of pelvic and acetabular surgery was developed by Cimerman \& Kristan in 2007 [75]. The program is currently being used for planning actual surgeries at the author's institution, University Medical Centre Ljubljana (Fig. 5c).

An interactive virtual reality orthopaedic surgery simulator was developed by Tsai et al. in 2001 [76] (Fig. 5d). The simulator allows surgeons to use various surgical instruments to operate on virtual rigid anatomic structures, such bones, prostheses and bone grafts, to simulate every procedure on the rigid structures for complex orthopaedic surgeries, including arthroplasty, corrective or open osteotomy, open reduction of fractures and amputation. A comparative study of 
the simulator with paper simulation was performed and showed that interns and residents found the simulator to be a useful learning tool, and that visiting doctors could use it effectively for planning, verification and rehearsal of operations.

A virtual reality ulna fracture fixation simulator using a Geomagic Premium ${ }^{13} 1.5$ 6DOF haptic device [83] was developed and tested by LeBlanc et al. in 2013 [77]. A stratified, randomized controlled study with 22 orthopaedic residents showed that significantly better scores were achieved on the virtual simulator compared with a synthetic manikin simulator. Both VR and synthetic simulators distinguished between differing experience levels, demonstrating construct validity ${ }^{14}$. The term construct validity refers to the ability of a simulator to assess the technical skills of the trainees [99]. Transfer validity ${ }^{15}$ is the ability of simulator learned skills to transfer into improved skill in-vivo [105]. Face validity measures how a simulator appears similar to the actual procedure.

Tonetti et al. (2009) [18] demonstrated a percutaneous iliosacral screw insertion simulator's efficiency in familiarizing the operator with the use of system as a first step towards the procedure in real patients. Twenty-three trainee orthopaedic surgeons were evaluated and the simulator was useful in the evaluation of surgical skills.

A basic low-fidelity arthroscopy skills simulator was developed by Braman et al. in 2014 [78]. A trial with 8 students and 8 surgeons demonstrated construct validity, showing that surgeons were faster than students, surgeons caused fewer errors, surgeons demonstrate higher steady state and consistency. Face validity ${ }^{16}$ was demonstrated by expert arthroscopists completing a questionnaire.

A computer-assisted planning system for orthopedic surgery developed by Furnstahl et al. in 2010 [79] used a delta. $6^{\mathrm{TM}}$ haptic device from Force Dimension ${ }^{17}$ (Switzerland) [80] proposed an algorithm for piecing together fragments of bone for the reconstruction of complex proximal humerus fractures.

A shoulder arthroscopy simulator, Mentis Procedicus uses custom made actuator controls with the arthroscope on left, and probe on right. A study validated the use of the VR simulation for the evaluation of surgical skills, and recommends their use for teaching surgery skills, including surgical anatomy and hand-eye coordination [81]. A group of ten psychology graduate students tested the Procedicus Virtual Arthroscopy knee trainer by Mentice Corp. (Sweden) and reported that they made steady improvements in task times with each session [82].

In order to compare the simulators, Tables 5 lists the other existing orthopaedic simulators with their various features.

\begin{tabular}{|c|c|c|c|c|c|c|c|c|c|}
\hline & $\stackrel{\bar{\Xi}}{\grave{Z}}$ & 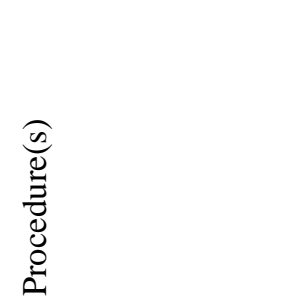 & 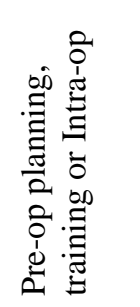 & 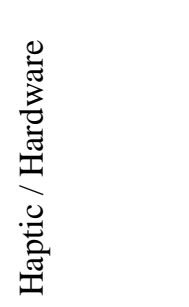 & 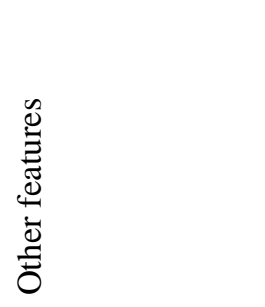 & 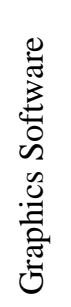 & 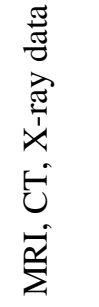 & 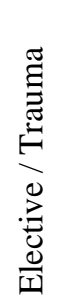 & 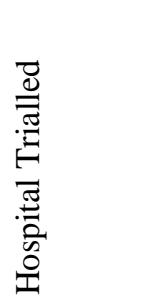 \\
\hline $\begin{array}{l}\text { Cimerman \& } \\
\text { Kristan [75] }\end{array}$ & 2007 & $\begin{array}{l}\text { Pelvic and } \\
\text { acetabular surgery }\end{array}$ & Pre-op & No & $\begin{array}{l}\text { Segmentation } \\
\text { tools. }\end{array}$ & $3 \mathrm{D}$ & $\mathrm{CT}$ & $\mathrm{E}$ & 22 cases \\
\hline $\begin{array}{l}\text { Sourin \& Sourina } \\
{[73,74]}\end{array}$ & 2000 & $\begin{array}{l}\text { Bone fracture. } \\
\text { virtual orthopaedic }\end{array}$ & $\begin{array}{l}\text { Pre-op, } \\
\text { Training }\end{array}$ & $\begin{array}{l}\text { Virtual } \\
\text { input/output }\end{array}$ & Standard PC. & $3 \mathrm{D}$ & $\begin{array}{l}\text { CT } \\
\text { MRI }\end{array}$ & $\mathrm{E}$ & No \\
\hline $\begin{array}{l}\text { Tsai et al. VR } \\
\text { orthopaedic sim } \\
\text { [76] }\end{array}$ & 2001 & $\begin{array}{l}\text { Orthopaedic + } \\
\text { arthroscopy }\end{array}$ & Pre-op & No & $\begin{array}{l}\text { Volumetric tissue } \\
\text { density }\end{array}$ & $3 \mathrm{D}$ & MRI & $\mathrm{E}$ & $\begin{array}{l}8 \text { residents } \\
4 \text { doctors }\end{array}$ \\
\hline $\begin{array}{l}\text { LeBlanc et al. } \\
\text { [77] }\end{array}$ & 2013 & $\begin{array}{l}\text { Ulna fracture } \\
\text { fixation }\end{array}$ & Training & $\begin{array}{l}\text { Geomagic } \\
\text { Premium1.5 } \\
{[83]}\end{array}$ & $\begin{array}{l}\text { No soft-tissue or } \\
\text { fracture reduction }\end{array}$ & $3 \mathrm{D}$ & No & $\mathrm{T}$ & $\begin{array}{l}20 \\
\text { residents }\end{array}$ \\
\hline Tonetti et al. [18] & 2009 & $\begin{array}{l}\text { Percutaneous } \\
\text { iliosacral screw }\end{array}$ & Training & No & $\begin{array}{l}\text { 3D CT images of } \\
\text { pelvis }\end{array}$ & $3 \mathrm{D}$ & CT & $\mathrm{E}$ & $\begin{array}{l}23 \\
\text { surgeons }\end{array}$ \\
\hline $\begin{array}{l}\text { Braman et al. } \\
\text { [78] }\end{array}$ & 2014 & $\begin{array}{l}\text { Basic arthroscopy } \\
\text { skills simulator }\end{array}$ & Training & No & Low fidelity & No & No & $E$ & $\begin{array}{l}8 \text { students } \\
8 \text { experts }\end{array}$ \\
\hline $\begin{array}{l}\text { Furnstahl et al. } \\
\text { [79] }\end{array}$ & 2010 & $\begin{array}{l}\text { Humerus fractures } \\
\text { orthopaedic }\end{array}$ & Pre-op & $\begin{array}{l}\text { Delta. } 6^{\mathrm{TM}} \\
\text { device. }[82]\end{array}$ & $\begin{array}{l}\text { 3D bone } \\
\text { angulation }\end{array}$ & $3 \mathrm{D}$ & MRI & $\mathrm{E}$ & $\begin{array}{l}\text { Positive } \\
\text { pilotstudy }\end{array}$ \\
\hline Pappas et al. [81] & 2008 & Shoulder & Training & Two custom & Evaluation, & $3 \mathrm{D}$ & No & $\mathrm{E}$ & 10 \\
\hline
\end{tabular}

\footnotetext{
${ }^{13}$ Geomagic Premium 1.5 Haptic Device [83]. 〈http://www.geomagic.com/en/products/phantom-premium/overview $>$

${ }^{14}$ Construct validity: the ability of a simulator to assess the technical skills of the trainees.

${ }^{15}$ Transfer validity: the ability of simulator learned skills to transfer into improved skill in-vivo.

${ }^{16}$ Face validity: measures how a simulator appears similar to the actual procedure.

${ }^{17}$ Force Dimension (Switzerland), delta. ${ }^{\mathrm{TM}}$ haptic device. 〈http://www.forcedimension.com/products/delta-6/overview >
} 


\begin{tabular}{|l|l|l|l|l|l|l|l|l|l|}
\hline $\begin{array}{l}\text { Mentis } \\
\text { Procedicus. }\end{array}$ & & arthroscopy & & arthroscopes & Random tasks & & & & graduates \\
\hline
\end{tabular}

Table 5. Other orthopaedic procedure surgery simulators

\section{Discussions}

\subsection{Challenges and current limitations of VR surgical training}

There are compelling reasons to apply VR to surgical training including the reduced reliance on patients, cadavers, and animals for practice. However, a review by Sutherland et al (2006) [85] suggests that none of the methods of simulated training has yet been shown to be better than other forms of surgical training. This indicates that improvements to efficacy and accuracy of virtual reality training would be beneficial and more studies may be required to assess and validate virtual reality training.

There are some limitations inherent with commercial haptic devices. Sensations of certain virtual surfaces are difficult to simulate in terms of density and palpable properties. Convex surfaces, such as bones, are difficult to recreate in a virtual environment, often giving the sensation of a slippery surface [86]. Further complicating the problem is the act of using a haptic device for drilling. The response rate of the device is too slow to emulate the correct vibration while drilling, leading to a drilling vibration which can only emulate vibrations below $1 \mathrm{kHz}$. Due to maximum force limitations in common haptic devices, some simulators require tailor made haptic devices. The high force knee arthroscopy haptic device by Zivanovic et al. in 2006 [72] performs with a higher force than commercial haptic devices are capable of. In particular to simulate hard objects, the novel use of a ball screw spline provides a maximum impedance of $20 \mathrm{~N} / \mathrm{mm}$ for translation as well as roll torque feedback in a small structure.

The accuracy of the forces in simulators must be high enough so that the simulated procedure matches the forces in reality. Skills learned during this simulation can then be transferred to the actual clinical environment.

Madan et al., [3] suggested in 2014 that further validation and efficacy studies are needed to demonstrate VR training translates into better operative skill on real patients.

\subsection{Disadvantages of conventional training methods}

During the 1500s, cadavers were introduced for surgical training and this remains the gold standard today, despite the possibility of disease transmission including tetanus, hepatitis B and tuberculosis. There are also high costs, difficulty of procurement, fresh cadavers have limited time of use, only a few centres nationally have cadaver facilities and there is varying validity depending on freshness and whether the cadaver is embalmed [5]. Cadavers which are embalmed are not very realistic for any testing as they can 'crumble' when surgical tools are inserted.

Recent educational expectations, advanced simulation technologies and heightened concerns for patient safety are creating a drive that will lead to rapid changes in surgical skills training [14].

Patient safety now receives increased emphasis and accountability within the medical profession [87]. Reports of the number of patient injury claims handled by the National Health Service Litigation Authority (NHSLA) between 1995 and 2010 highlight the potential morbidity from surgery but also the substantial cost burden to the NHS. Worldwide, hip fractures account for substantial healthcare costs and high mortality, morbidity, and reoperation rates [88].

Apprenticeships have conventionally enabled trainees to participate and learn arthroscopy skills in-vivo on patients during scheduled operating slots. For apprentices the operating theatre was the site of orthopaedic training. For the experts, teaching apprentices is difficult when simultaneously applying complex motor skills. Orthopaedic treatments have become increasingly difficult due to use of minimal access techniques and laparoscopic and arthroscopic surgery [21]. Research has shown that presence of trainees prolongs operative cases and requires increased resources in the operating room, but does not influence complication rates [89]. Surgeons are required to work at maximum efficiency, placing time constraints on the amount of teaching that can be achieved in the operating theatre.

There is an increased error rate when trainees perform procedures. For these reasons, non-clinical training methods for arthroscopic procedures have been a focus in the literature. Animal or cadaver based training is expensive and requires additional specimen handling processes. Low fidelity simulators exist but lack the sophistication to replicate advanced techniques. Virtual reality simulators have been outlined as the next possible improvement for orthopaedic training, reducing costs of training and improving patient safety. However in order to become a mainstream component of training, efficacy studies are required, to measure skill development of novices to show that simulators improve the in-vivo performance.

\subsection{Positive opinions amongst surgeons for use of VR training}


Orthopaedic surgeons are optimistic about virtual reality being used for training. A postal survey by Blyth et al. in 2006 [90] was sent out to all orthopaedic surgeons in New Zealand and 142 responses were received. Of the earlier qualified surgeons $77 \%$ agree that simulation was an effective way to practice surgical procedures. The group identified that realistic view of the operation was the most important requirement.

An email survey by the American Academy of Orthopaedic Surgeons (AAOS) was sent to 185 program directors and 4549 residents, with a response rate of $46 \%$ directors and $15 \%$ residents. Both $80 \%$ of program directors and $86 \%$ of residents agreed that surgical skills simulations should become a required part of orthopaedic training, and $82 \%$ and $76 \%$ were interested in a standardized surgical skills curriculum. Currently $83 \%$ of residents believed that surgical skill was not being objectively measured, perhaps due to only $34 \%$ of directors having established a structured laboratory curriculum. There was a strong agreement that simulation technology should be a required component of orthopaedic resident training [91].

A trial by Tillander et al. in 2004 [92] evaluated a virtual reality hip trauma simulator and found that all participants thought that simulators should be part of training programs and simulators would help to learn procedures.

There is little doubt that as simulation technology becomes commercially more economical, computer simulations or virtual reality will play a greater role in skills training in surgery and indeed across the whole of medicine, becoming a feature of assessment and even accreditation [93].

\subsection{Does VR surgery simulator use translate into better clinical performance and patient safety?}

Evidence for the educational value of VR surgical simulators is accumulating rapidly. Several studies have provided verification of simulator validity and have shown the transfer of simulator-acquired skill to the operating room. Frank et al. (2014) [4] reviewed 19 existing arthroscopy training simulators evaluating task performance before and after: $75 \%$ of validation studies showed improvement after simulator training. Tillander et al., (2004) [92] demonstrated that positioning of hip nails improved between the first and last trial on a virtual reality hip trauma simulator and also the total surgery and fluoroscopy time were reduced. A review of arthroscopic simulators by Shantz et al. [21] was completed in 2014 to identify whether simulators improve surgical skills of users. The study recommends that international standards should be developed for the use and effectiveness of simulators in orthopaedic surgery. The transfer of skills from simulators to invivo is further discussed in a review of orthopaedic simulator transfer validity by Vaughan et al. (2015) [106].

\subsection{Can VR surgery simulators assess the skill level of trainees?}

There is strong evidence showing that simulators can distinguish between trainees of differing skill levels and could objectively assess trainees. Experienced surgeons can complete VR simulated surgery faster than students, demonstrated by Tillander et al. (2004) [92]. Pedowitz et al. (2002) [98] evaluated a shoulder arthroscopy simulator (Mentice Corp, Sweden) showing that test time and path ratio differed significantly as a function of surgical experience, demonstrating that the simulator facilitates discrimination of arthroscopic skills. All of the reviewed arthroscopy simulator validations have reported 100\% positive correlation between experience level and simulator performance [4]. A review in 2014 by Shantz [21] has shown arthroscopic VR simulators are able to discriminate between novice and experts. Arthroscopic Surgical Skill Evaluation Tool (ASSET) is reported to be a reliable method for assessing performance of trainee surgeons for diagnostic knee arthroscopic surgery in cadaveric specimens [94]. A review of skill level assessment in VR simulators by Vaughan et al. (2015) [99] outlines many other studies which have clearly demonstrated that the skill level of trainees can be assessed by VR simulators in a variety of medical procedures, which is referred to as construct validity.

\subsection{What is the future aim and requirements of surgical simulation?}

Stefanidis et al. (2012) state that the future research agenda and priority research questions for simulated surgery needs to define coordinated efforts and clarify common goal and direction [95]. Studies are required to present evidence validating whether or not simulators can improve patient outcomes, transfer to improved clinical performance and competence, leading to increased patient safety.

More studies are required to comment on the learning curve or the number of training sessions needed to translate simulated learned skills into the operating room [3].

\subsection{Comparison between VR and physical training methods}


In terms of training for orthopaedic surgery, there are three main methods: VR, physical manikin models and human cadavers, each with advantages and disadvantages. As Virtual Reality becomes increasingly realistic and patient-specific the advantages to VR are increasing rapidly. Manikin simulators are also being regularly developed but do not seem to be progressing so rapidly; manikins have also been combined with VR for hybrid simulators. Cadaver training is not improving although it has been used for the longest time. Features of the three main training methods are compared and contrasted in Table 6.

\begin{tabular}{|l|l|}
\hline Training Method & Advantages and Disadvantages \\
\hline Virtual Reality & $\begin{array}{l}\text { Advantages: Variation in shape and size is easily achieved using a button or slider. 3D anatomy can be } \\
\text { patient-specific generated from CT or MRI [35]. Surgeons can determine implant position using CT images } \\
\text { [35]. Kinematic joint models can predict joint motion [35]. VR can be used clinically in-vivo for interactive } \\
\text { surgical navigation [35]. Haptic device feedback can enhance training [49]. Actual surgical tools can be used } \\
\text { [49]. Realistic 3D stereo graphics can show internal anatomy. Abnormal cases can be modelled. There is no } \\
\text { risk to patients [39]. No expert trainer is required. Assessment and feedback automated based on curriculum. } \\
\text { Based on actual patient MRI images [39]. Movable functional joint model [39]. Deformation modelling of } \\
\text { soft tissues and cartilage [39]. Disadvantages: Haptic devices require data from actual surgery to configure } \\
\text { accuracy. Optical tracking systems require setup [39]. }\end{array}$ \\
\hline Physical Manikins & $\begin{array}{l}\text { Advantages: Physically represents the visual appearance and shape of in vivo [47]. Can include body fluid. } \\
\text { There is no risk to patients. Disadvantages: Variation in shape and size requires different models. Parts } \\
\text { require replacing when worn. Materials may not represent human tissue accurately. An expert trainer may be } \\
\text { required to explain the procedure. Assessment and scoring must be done manually. }\end{array}$ \\
\hline Human Cadaver & $\begin{array}{l}\text { Advantages: Similar appearance to in-vivo surgery. Used for 500 years. There is no risk to patients. } \\
\text { Disadvantages: Expensive. Difficult to acquire. Ethical considerations. Fresh cadavers have limited time of } \\
\text { use. Degrading tissue over time. Risk of disease transmission (tetanus, hepatitis B, tuberculosis). Only a few } \\
\text { national centres have cadaver facilities. Varying validity depending on freshness. Cadavers which are } \\
\text { embalmed are not very realistic for any testing as they can 'crumble' when surgical tools are inserted. An } \\
\text { expert trainer may be required to explain the procedure. Assessment and scoring must be done manually. }\end{array}$ \\
\hline
\end{tabular}

Table 6. Comparison and contrast of the various types of VR, manikin and cadaver training.

\subsection{Specification for an ideal VR training simulator for orthopaedic surgery}

An ideal simulator should be multimodal, combining haptic, visual and audio technology to create an immersive training environment. An example of a gold standard simulator are those employed by the aviation industry, whereby the simulated flight cockpit includes noise, vision and motion giving a real sense of flying an actual plane in differing weather conditions.

Assessment of trainees' skill level and performance feedback is an advantage in an ideal simulator, since VR is proven to assess skill level [99]. When simulators are used as part of an assessment, the application of structured assessment criteria, or a curriculum-based assessment such as Knowledge Space Theory (KST) can provide a framework for objective feedback. If assessment criteria are applied, simulators can form a useful part of training and as a Simulated Interactive Learning System (SILS).

Patient-specific simulators are becoming more important. Data from MRI or CT data can be incorporated into simulators using software for medical image processing and visualization, such as MIPAV [24], MITK [25] or 3DSlicer [26]. These enable volumetric patient scans to directly be used for virtual simulation, or for 3D printing custom fit biocompatible implants for surgical use.

Hybrid training simulators are being developed, which combine physical body models and actual surgical tools with VR simulators. This adds the advantages of using realistic tools, addition of bodily fluid and physical materials, yet still retains the advantages of VR such as viewing the 3D anatomy, assessment and patient-specific modelling.

Kinematic joint models are useful to predict joint motion especially when combined with tissue deformation modelling. These models enable analysis of the best implant position for the patient.

Stereo graphics and head mounted displays (HMDs) such as Oculus Rift are improving the realism of simulators with features such as head tracking and eye tracking.

Transfer of expert skills is important and haptic devices can help this by recording motion and force of surgical instruments during an expert performance, and applying haptic guidance to guide the trainee during surgery simulation.

Abnormal clinical cases and complications can be modelled in VR, enabling practice at the trainee's own speed. This enables preparation for unusual cases in-vivo.

An important future capability of VR is the ability to be used during in-vivo surgery as surgical guidance. Haptic training is increasingly related to robot assisted surgery and could be useful in tele-operative training and surgery. 
Haptic simulators increasingly incorporate measured data from in-vivo procedures to ensure the haptic feedback is representative of the actual procedure. The haptic accuracy can then be measured and compared with the accuracy of synthetic materials in manikin models, or with simulators configured by expert adjustment.

These features form a specification as a target and challenge to the research and industrial community which may continue to develop in future VR simulator training research.

\section{Conclusions}

This review identifies that there are only limited training simulators for total hip replacement and resurfacing. This is surprising since over 66,000 surgeries are performed annually in the UK. There are two main problems with hip surgery which simulators could aim to improve: One problem is that dislocation rate is $2-6 \%$ following primary total hip replacement (THR). Secondly impingement between the neck of the femoral implant and the rim of the acetabular component causes advanced wear of the acetabular rim. The primary cause for both these problems is incorrect acetabular positioning during surgery, and a training simulator could enable practice of this technique, reducing the risk of patients requiring revision surgery.

Future studies would be useful focussing on gaining evidence for whether surgical skills gained in a simulator can be transferred to improved skill on actual patients [85]. Efficacy studies could be conducted to follow the progress of two cohorts of surgeons, one trained with virtual reality training and one with the conventional methods, to enable a comparison between the two cohorts of the injury and failure rate, plus confidence levels. Ethical considerations would be required when running such efficacy studies, considering that it is not permitted to indirectly deny patients better treatment. Training with virtual reality may improve the ability of surgeons during in-vivo surgery.

Patient-specific virtual reality is currently increasing and can enable surgeons to practice beforehand on a virtual model of a specific patient thereby reducing the learning curve during the in-vivo procedure. Patient-specific body shape graphical models have been developed containing the thickness of tissue layers for various BMIs by Vaughan et al. [100], [101]. Patient-specific modelling is demonstrated by simulators which include the ability to practice custom manufacturing implant components to fit individual patients. A model proposed by Abbaszadeh et al. in 2011 [102] uses $3 \mathrm{D}$ data from a patient's femur CT scan to model a custom-made femoral stem based on the 3D shape of the internal cavity from CT data. Custom designed implant simulation is also demonstrated by Jun et al., (2012) [67] who developed a simulator allowing custom fit knee replacement using knee models reconstructed from 3D patient CT scans. Another example of simulation using patient-specific implants is the VIRTOPS orthopaedic simulator by Handels et al., [45,46] which supports the individual design of anatomically adaptable, modular customised prostheses stems. The use of patientspecific implants is set to further increase, both in-vivo and in-vitro simulation as well as surgery. This is particularly useful in complex cases where standard implants are not suitable such as revision surgery. The design and manufacture of customised and patient-specific implants is aided by software to convert anatomical data from MRI and CT scans into data that can be used in CAD systems [23-29]. These CAD models can then be used with Additive Manufacturing / 3D printing to produce patient specific anatomical models, surgical guides and custom fitting implants.

\section{Figure Source Permissions}

The following figures were reprinted from previous publications with kind permission from the sources shown in Table 7 .

\begin{tabular}{|l|l|l|l|l|l|}
\cline { 2 - 6 } \multicolumn{1}{|l}{} & a & b & c & d & e \\
\hline Fig. 2. & Materialise [23] & Edheads [30], [31]. & $\begin{array}{l}\text { Springer. (Jun \& Park } \\
\text { 2011) [33] }\end{array}$ & $\begin{array}{l}\text { Springer. (Dick et } \\
\text { al., 2010) [34]. }\end{array}$ & $\begin{array}{l}\text { Elsevier. (Digioia et } \\
\text { al., 2000) [35] }\end{array}$ \\
\hline Fig. 3. & $\begin{array}{l}\text { John Wiley and Sons. } \\
\text { (Assassi et al., 2009) [39] }\end{array}$ & $\begin{array}{l}\text { Elsevier. (Taylor et } \\
\text { al., 2009) [41] }\end{array}$ & $\begin{array}{l}\text { Japanese Orthopaedic } \\
\text { Association, Springer. } \\
\text { (Nishihara et al., 2003) } \\
\text { [43] }\end{array}$ & $\begin{array}{l}\text { Elsevier. (Handels } \\
\text { et al. 2000) [45], } \\
\text { [46]. }\end{array}$ & $\begin{array}{l}\text { Elsevier. (Tsai et } \\
\text { al., 2007) [48] }\end{array}$ \\
\hline Fig. 4. & $\begin{array}{l}\text { Elsevier. (Vankipuram et al., } \\
\text { 2010) [50] }\end{array}$ & Traumavision. [96] & $\begin{array}{l}\text { IOSPress and authors, } \\
\text { (Barrow et al., 2012) } \\
\text { [53] }\end{array}$ & $\begin{array}{l}\text { Elsevier. (Blyth et } \\
\text { al., 2008) [56] }\end{array}$ & $\begin{array}{l}\text { Elsevier. (Rambani } \\
\text { et al., 2013) [58] }\end{array}$ \\
\hline Fig. 5. & $\begin{array}{l}\text { Springer Science + Business } \\
\text { Media. (Jun et al., 2012) [67] }\end{array}$ & $\begin{array}{l}\text { Elsevier. } \\
\text { (Cimerman et al., } \\
\text { 2007) [75] }\end{array}$ & $\begin{array}{l}\text { Springer. (Mabrey et al., } \\
\text { 2010) [68] }\end{array}$ & $\begin{array}{l}\text { Elsevier. (Tsai et } \\
\text { al., 2001) [76] }\end{array}$ & \\
\hline
\end{tabular}

Table 7. Permission sources for figures re-printed from other publications. 


\section{Acknowledgements}

This research review was completed with funding from Wessex Academic Health Science Network (Wessex AHSN) Innovation and Wealth Creation Accelerator Fund 2014/15 and funding from Bournemouth University.

\section{Conflict of interests}

No conflict of interests has been declared.

\section{Copyright Information}

(C) 2015. This manuscript version is made available under the CC-BY-NC-ND 4.0 license http://creativecommons.org/licenses/by-nc-nd/4.0/

Please cite this article as: N.Vaughan et al., A review of virtual reality based training simulators for orthopaedic surgery, Medical Engineering and Physics (2015), http://dx.doi.org/10.1016/j.medengphy.2015.11.021

\section{References}

[1] Johns BD. PhD Thesis. The creation and validation of an augmented reality orthopaedic drilling simulator for surgical training. University of Iowa, May 2014.

[2] Rambani R, Ward J, Viant W. Desktop-Based Computer-Assisted Orthopedic Training System for Spinal Surgery. Journal of surgical education 2014;71(6):805-9.

[3] Madan SS, Pai, DR. Role of Simulation in Arthroscopy Training. Simulation in Healthcare: The Journal of the Society for Simulation in Healthcare 2014;9(2):127-35.

[4] Frank RM, Erickson B, Frank JM, Bush-Joseph CA, Bach Jr BR, Cole BJ, Romeo AA, Provencher MT, Verma, NN. Utility of Modern Arthroscopic Simulator Training Models. Arthroscopy: The Journal of Arthroscopic \& Related Surgery 2014;30(1):121-33.

[5] Levine AI, DeMaria Jr S, Schwartz AD, Sim AJ. The Comprehensive Textbook of Healthcare Simulation, Springer Science \& Business Media; 2013.

[6] Kelsey JL, Hoffman S. Risk factors for hip fracture. The New England journal of medicine 1987;145(9):786-93.

[7] Cummings SR, Rubin SM, Black D. The future of hip fractures in the United States: numbers, costs, and potential effects of postmenopausal estrogen, Clinical Orthopaedics and Related Research 1990;252:163-6.

[8] Tosteson AN, Burge RT, Marshall DA, Lindsay R. Therapies for Treatment of Osteoporosis in US Women: Costeffectiveness and Budget Impact Considerations-Page 4, Am J Manag Care 2008;14:605-15.

[9] Cooper C, Campion G, Melton III L. Hip fractures in the elderly: a worldwide projection, Osteoporosis international 1992;2:285-9.

[10] Morrey BF (editor). Reconstructive Surgery of the Joints, Chapter, Joint Replacement Arthroplasty, Churchill Livingston; 1996: 605-8.

[11] Maher SA, Lipman JD. Influence of acetabular rim profile on hip dislocation. Proceedings of the Institution of Mechanical Engineers, Part H: Journal of Engineering in Medicine 2006;220(8);881-7.

[12] Willert HG, Buchhorn GH, Fayyazi A, Flury R, Windler M, Köster G, Lohmann CH. Metal-on-metal bearings and hypersensitivity in patients with artificial hip jointsA clinical and histomorphological study. The Journal of Bone \& Joint Surgery 2005;87(1):28-36.

[13] Akhtar KSN, Chen A, Standfield NJ, Gupte CM. The role of simulation in developing surgical skills. Current reviews in musculoskeletal medicine 2014;7(2):155-160.

[14] Pedowitz RA, Marsh JL Motor skills training in orthopaedic surgery: a paradigm shift toward a simulation-based educational curriculum. Journal of the American Academy of Orthopaedic Surgeons 2012;20(7):407-9.

[15] Seymour NE, Gallagher AG, Roman SA, O’Brien MK, Bansal VK, Andersen DK, Satava RM. Virtual reality training improves operating room performance: results of a randomized double-blinded study. Ann Surg 2002;236:458-63.

[16] Gurusamy K, Aggarwal R, Palanivelu L, Davidson BR. Systematic review of randomized controlled trials on the effectiveness of virtual reality training for laparoscopic surgery. Br J Surg. 2008;95:1088-97. 

software in orthopaedic surgical planning: advantages and limitations. Computerized medical imaging and graphics 1994;18(6):435-42.

[18] Tonetti J, Vadcard L, Girard P, Dubois M, Merloz P, Troccaz J. Assessment of a percutaneous iliosacral screw insertion simulator. Orthopaedics \& Traumatology: Surgery \& Research 2009;95(7):471-7.

[19] J Pettersson, Palmerius KL, Knutsson H, Wahlstrom O, Tillander B, Borga M, Simulation of Patient Specific Cervical Hip Fracture Surgery With a Volume Haptic Interface, IEEE Transactions on Biomedical Engineering 2008;55:1255-65.

[20] Hohn EA, Brooks AG, Leasure J, Camisa W, van Warmerdam J, Kondrashov, D, Montgomery W, McGann W. Development of a Surgical Skills Curriculum for the Training and Assessment of Manual Skills in Orthopedic Surgical Residents. Journal of surgical education 2015;1:47-52.

[21] Shantz JAS, Leiter JR, Gottschalk T, MacDonald PB. The internal validity of arthroscopic simulators and their effectiveness in arthroscopic education. Knee Surgery, Sports Traumatology, Arthroscopy 2014;22(1):33-40.

[22] Vaughan N, Dubey VN, Wee MYK, Isaacs R. A review of epidural simulators: Where are we today? Medical engineering \& physics 2013;35(9):1235-50.

[23] Materialise (2014) Mimics Innovation Suite. Available at: http://biomedical.materialise.com/mis (Accessed: 18 December 2015).

[24] Medical Image Processing and Visualization. Available at: http://mipav.cit.nih.gov/ (Accessed: 18 December 2015).

[25] Medical Imaging Interaction Toolkit Workbench. Available at: http://mitk.org (Accessed: 18 December 2015).

[26] 3DSlicer Medical Imaging Software. Available at: http://www.slicer.org (Accessed: 18 December 2015).

[27] Simpleware 3D image data visualisation, analysis and model generation software. Available at: http://www.simpleware.com/software (Accessed: 18 December 2015).

[28] 3D Doctor Modelling, image processing and measurement software for MRI, CT, PET, microscopy. Available at: http://www.ablesw.com/3d-doctor (Accessed: 18 December 2015).

[29] OsiriX Imaging Software, Open-Source PACS and DICOM Viewer. Available at: http://www.osirixviewer.com (Accessed: 18 December 2015).

[30] EdHeads (2007) Hip Replacement Online Game 1. Available at: http://www.edheads.org/activities/hip/ (Accessed: 18 December 2015).

[31] EdHeads (2007) Hip Resurfacing Online Game 2. Available at: http://www.edheads.org/activities/hip2/ (Accessed: 18 December 2015).

[32] Sato Y, Sasama T, Sugano N, Nakahodo K, Nishii T, Ozono K, Tamura S. Intraoperative simulation and planning using a combined acetabular and femoral (CAF) navigation system for total hip replacement. In Medical Image Computing and Computer-Assisted Intervention-MICCAI. Springer Berlin Heidelberg. 2000:1114-25.

[33] Jun Y, Park S. Polygon-based 3D surgical planning system for hip operation. International Journal of Precision Engineering and Manufacturing 2011;12(1):157-60.

[34] Dick C, Georgii J, Burgkart R, Westermann R. A 3D simulation system for hip joint replacement planning. In World Congress on Medical Physics and Biomedical Engineering. Springer Berlin Heidelberg. 2010:363-6.

[35] Digioia AM, Jaramaz B, Nikou C, Labarca RS, Moody JE, Colgan BD. Surgical navigation for total hip replacement with the use of HipNav. Operative Techniques in Orthopaedics 2000;10(1):3-8.

[36] Digioia AM, Simon D, Jaramaz B, Blackwell M, Morgan FM, O'Toole RV, Bruce Colgan, and Eric Kischell, HipNav: Pre-operative Planning and Intra-operative Navigational Guidance for Acetabular Implant Placement in Total Hip Replacement Surgery, Computer Assisted Orthopaedic Surgery Symposium 1995.

[37] Sinha RK Hip replacement: current trends and controversies. CRC Press. 2002.

[38] Digioia A, Jaramaz B, Blackwell M, Simon D, Morgan F, Moody JE, Nikou C, Colgan B, Aston C, Labarca R, Kischell E, Kanade T. Image guided navigation system to measure intraoperatively acetabular implant alignment. Clin Orthop Rel Res. 1998;355:8-22.

[39] Assassi L., Charbonnier C, Schmid J, Volino P, Magnenat-Thalmann N. From MRI to anatomical simulation of the hip joint. Computer Animation and Virtual Worlds 2009;20(1):53-66.

[40] Pollard TC, Khan T, Price AJ, Gill H S, Glyn-Jones S, Rees JL. Simulated Hip Arthroscopy Skills: Learning Curves with the Lateral and Supine Patient Positions: A Randomized Trial. The Journal of Bone \& Joint Surgery 2012;94(10):68. 
[41] Taylor RH, Joskowicz L, Williamson B, Guéziec A, Kalvin A, Kazanzides P, Lahmer, A. Computerintegrated revision total hip replacement surgery: concept and preliminary results. Medical image analysis 1999;3(3):301-19.

[42] Pransky J. ROBODOC-surgical robot success story. Industrial Robot: An International Journal 1997;24(3):231-3.

[43] Nishihara S, Sugano N, Nishii T, Tanaka H, Yoshikawa H. Comparison of the fit and fill between the Anatomic Hip femoral component and the VerSys Taper femoral component using virtual implantation on the Orthodoc workstation. Journal of orthopaedic science 2003;8(3):352-60.

[44] Savuc G, Forna D, Forna NC. The Contribution of Medical Robots to Clinical Performance: Up-to-date. Romanian Journal of Oral Rehabilitation 2012;4(4):67.

[45] Handels H, Ehrhardt J, Plötz W, Pöppl SJ. Virtual planning of hip operations and individual adaption of endoprostheses in orthopaedic surgery. International journal of medical informatics 2000;58:21-8.

[46] Handels H, Ehrhard J, Plötz W, Pöppl SJ. Three-dimensional planning and simulation of hip operations and computer- assisted construction of endoprostheses in bone tumor surgery. Computer Aided Surgery 2001;6(2):65-76.

[47] Sawbones (2014). Mannikin based hip arthrosopy bench-top simulator. Available at: http://www.sawbones.com/Catalog/Orthopaedic\%20Models/Hip/9077-9 (Accessed: 18 December 2015).

[48] Tsai MD, Hsieh MS, Tsai $\mathrm{CH}$, Bone drilling haptic interaction for orthopedic surgical simulator. Computers in Biology and Medicine 2007;37:1709-18.

[49] Geomagic (2014) Touch X haptic device. Available at: http://www.geomagic.com/en/products/phantomdesktop/overview (Accessed: 18 December 2015).

[50] Vankipuram M, Kahol K, McLaren A, Panchanathan S, A Virtual Reality Simulator for Orthopedic Basic Skills: A Design and Validation Study. J Biomedical Informatics 2010;43(5):661-8.

[51] Froelich JM, Milbrandt JC, Novicoff WM, Saleh KJ, Allan DG. Surgical simulators and hip fractures: a role in residency training?. Journal of Surgical Education 2011;68(4):298-302.

[52] HOOT Imperial College London (2014), HOOT Simulator by Imperial College London. Available at: http://www1.imperial.ac.uk/simms/research/procedure_modelling_simulation/hoot/ (Accessed: 18 December 2015).

[53] Barrow A, Akhtar K, Gupte C, Bello F. Requirements analysis of a 5 degree of freedom haptic simulator for orthopedic trauma surgery. Studies in health technology and informatics 2012;184:43-7.

[54] Blyth P, Stott NS, Anderson IA. A simulation-based training system for hip fracture fixation for use within the hospital environment. Injury 2007;38:1197-1203.

[55] Blyth P. PhD Thesis. A Virtual Reality simulator for Hip Surgery. University of Auckland. November 2008.

[56] Blyth P, Stott NS, Anderson IA. Virtual reality assessment of technical skill using the Bonedoc DHS simulator. Injury 2008;39:1127-33.

[57] Blyth P, Sehgal P. Use of the Bonedoc DHS simulator by fifth year medical students: A pilot study. In Proceedings of ASCILITE - Australian Society for Computers in Learning in Tertiary Education Annual Conference 2009:74-80.

[58] Rambani R, Viant W, Ward J, Mohsen A. Computer-assisted orthopedic training system for fracture fixation. Journal of surgical education 2013;70(3):304-308.

[59] Linköping University, Sweden, 2012. Haptic Simulation of Hip Fracture Surgery, Available at: http://www.imt.liu.se/mi/Research/simulator (Accessed: 18 December 2015)

[60] Wrangsjö A, Pettersson J, Knutsson H, Non-Rigid Registration Using Morphons. Springer Berlin Heidelberg Image Analysis 2005:501-10.

[61] Pettersson J, Knutsson H, Nordqvist P, Borga M. A hip surgery simulator based on patient specific models generated by automatic segmentation. Studies in health technology and informatics 2005;119:431.

[62] Pettersson J, Knutsson H, Borga M, Generation of Patient Specific Bone Models from Volume Data Using Morphons, In IFMBE Proceedings: NBC'05 13th Nordic Baltic Conference Biomedical Engineering and Medical Physics 2005:199-200.

[63] Pettersson J, Knutsson H, Borga M. Automatic hip bone segmentation using non-rigid registration. IEEE 18th International Conference on Pattern Recognition 2006. ICPR 2006;3:946-9.

[64] Tseng CH. PhD Thesis. On the development of a computer-assisted patient-doctor relationship and preoperative evaluation system for hip surgery. National Central University Taiwan. July 2011. 
[65] Ascension (2014), 3D Guidance trakSTAR ${ }^{\mathrm{TM}}$ 6-DOF. Available at: http://www.ascensiontech.com/products/trakstar-drivebay (Accessed: 18 December 2015).

[66] Northern Digital Inc. (2015) Polaris optical tracking system. Available at: http://www.ndigital.com/medical/products/polaris-family (Accessed: 18 December 2015).

[67] Jun Y, Lee KY, Gwak KW, Lim D. Anatomic basis 3-D surgical simulation system for custom fit knee replacement. International Journal of Precision Engineering and Manufacturing 2012;13(5):709-15.

[68] Mabrey JD, Reinig KD, Cannon WD. Virtual reality in orthopaedics: is it a reality?. Clinical Orthopaedics and Related Research 2010;468(10):2586-91.

[69] Heng PA, Cheng CY, Wong TT, Xu Y, Chui YP, Chan KM, Tso SK. A virtual-reality training system for knee arthroscopic surgery. IEEE Transactions on Information Technology in Biomedicine 2004;8(2):217-27.

[70] Mabrey JD, Cannon WD, Gillogly SD, Kasser JR, Sweeney HJ, Zarins B, Poss, R. Development of a virtual reality arthroscopic knee simulator. Studies in Health Technology and Informatics 1999;70:192-4.

[71] McCarthy AD, Moody L, Waterworth AR, Bickerstaff DR. Passive haptics in a knee arthroscopy simulator: is it valid for core skills training? Clin Orthop Relat Res. 2006;442:13-20.

[72] Zivanovic A, Dibble E, Davies B. A high force haptic system for knee arthroscopy training. International Journal of Humanoid Robotics 2006;3(4):429-37.

[73] Sourin A, Sourina O, Sen HT. Virtual orthopedic surgery training. IEEE Computer Graphics and Applications 2000;20:6-9.

[74] Sourina O, Sourin A, and Sen HT, Virtual orthopedic surgery training on personal computer. International Journal of Information Technology 2000;6:16-29.

[75] Cimerman M, Kristan A. Preoperative planning in pelvic and acetabular surgery: the value of advanced computerised planning modules. Injury 2007;38(4):442-9.

[76] Tsai MD, Hsieh MS, Jou SB, Virtual reality orthopedic surgery simulator. Computers in biology and medicine 2001;31:333-51.

[77] LeBlanc J, Hutchison C, Hu Y, Donnon T. A comparison of orthopaedic resident performance on surgical fixation of an ulnar fracture using virtual reality and synthetic models. The Journal of Bone \& Joint Surgery 2013;95(9):60-1.

[78] Braman JP, Swee RM, Hananel DM, Ludewig PM, Van Heest AE. Development and Validation of a Basic Arthroscopy Skills Simulator. Arthroscopy: The Journal of Arthroscopic \& Related Surgery 2014;31(1):104-12.

[79] Furnstahl P. PhD Thesis. Computer-assisted planning for orthopedic surgery. Eidgenössische Technische Hochschule ETH Zürich, Nr. 19102, 2010.

[80] Force Dimension (Switzerland), delta.6 ${ }^{\mathrm{TM}}$ haptic device. Available at: http://www.forcedimension.com/products/delta-6/overview (Accessed: 18 December 2015).

[81] Pappas G, Gomoll AH, Forsythe B, Warner JJ. Virtual Reality Simulation for Shoulder Arthroscopy. Orthopaedic Journal at Harvard Medical School 2008;10:95-8.

[82] Bliss JP, Hanner-Bailey HS, Scerbo MW (2005) Determining the efficacy of an immersive trainer for arthroscopy skills. Stud Health Technol Inform. 2005;111:54-6.

[83] Geomagic (2015) Premium $\underline{1.5}$ Haptic Device. Available at: http://www.geomagic.com/en/products/phantom-premium/overview (Accessed: 18 December 2015).

[84] Geomagic (2015) Touch Haptic Device. Available at: http://www.geomagic.com/en/products/phantomomni/overview (Accessed: 18 December 2015).

[85] Sutherland LM, Middleton PF, Anthony A, Hamdorf J, Cregan P, Scott D, Maddern GJ. Surgical simulation: a systematic review. Annals of surgery 2006;243(3):291.

[86] Mark WR, Randolph SC, Finch M, Van Verth JM, Taylor RM. II, Adding force feedback to graphics systems: Issues and solutions. in Proceedings of the 23rd annual conference on Computer graphics and interactive techniques 1996:447-52.

[87] Bould MD, Crabtree NA, Naik VN. Assessment of procedural skills in anaesthesia. Br J Anaesth 2009;103:472-83.

[88] Pedersen P, Palm H, Ringsted C, Konge L. Virtual-reality simulation to assess performance in hip fracture surgery. Acta orthopaedica 2014, 85(3),1-5.

[89] Haughom BD, Schairer WW, Hellman MD, Yi PH, Levine BR. Resident Involvement Does Not Influence Complication After Total Hip Arthroplasty: An Analysis of 13,109 Cases. The Journal of Arthroplasty 2014;29(10):1919-24. 
[90] Blyth P, Anderson IA, Stott NS. Virtual reality simulators in orthopedic surgery: what do the surgeons think?. Journal of Surgical Research 2006;131(1):133-9.

[91] Karam MD, Pedowitz RA, Natividad H, Murray J, Marsh JL. Current and future use of surgical skills training laboratories in orthopaedic resident education: a national survey. The Journal of Bone \& Joint Surgery 2013;95(1):e4.

[92] Tillander B, Ledin T, Nordqvist P, Skarman E, Wahlström O. A virtual reality trauma simulator. Medical teacher 2004;26(2):189-91.

[93] Torkington J, Smith SG, Rees BI, Darzi A. The role of simulation in surgical training. Annals of the Royal College of Surgeons of England 2000;82(2):88.

[94] Koehler RJ, Amsdell S, Arendt EA, Bisson LJ, Bramen JP, Butler A, Cosgarea AJ. The Arthroscopic Surgical Skill Evaluation Tool (ASSET). The American journal of sports medicine 2013;41(6):1229-37.

[95] Stefanidis D, Arora S, Parrack DM, Hamad GG, Capella J, Grantcharov T, Jones DB. Research priorities in surgical simulation for the 21st century. The American Journal of Surgery 2012;203(1):49-53.

[96] Swemac Traumavision $\underline{\text { (2014) }}$ Swemac $\quad$ Traumavision. Available http://www.swemac.com/simulators/traumavision (Accessed: 18 December 2015).

[97] BoneDoc (2014) About the BoneDoc Simulator. Available at: http://bonedoc.org/about.html (Accessed: 18 December 2015).

[98] Pedowitz RA, Esch J, Snyder S. Evaluation of a virtual reality simulator for arthroscopy skills development. Arthroscopy. 2002;18:e29.

[99] Vaughan N, Dubey VN, Wainwright TW, Middleton RG., Can virtual-reality simulators assess experience and skill level of orthopaedic surgeons?. IEEE Science and Information Conference (SAI) 2015:113.

[100] Vaughan N, Dubey VN, Wee MYK, Isaacs R. Epidural Simulation for Patients of Various BMI and Body Shapes. Journal of Medical Devices 2013;7(3):30924.

[101] Vaughan N, Dubey VN, Wee MYK, Isaacs R. Parametric model of human body shape and ligaments for patient-specific epidural simulation. Artificial intelligence in medicine 2014;62(2):129-40.

[102] Abbaszadeh F, Rahmati S, Kheirollahi H, Farahmand F. Design for manufacturing of custom-made femoral stem using CT data and rapid prototyping technology. International Journal of Rapid Manufacturing 2011;2(1):76-91.

[103] Simendo (2006) arthroscopy trainer. Available at: http://www.simendo.eu/ (Accessed: 18 December 2015).

[104] Verdaasdonk EGG, Stassen LPS, Monteny LJ, Dankelman J, Validation of a new basic virtual reality simulator for training of basic endoscopic skills. Surgical Endoscopy and Other Interventional Techniques 2006;20(3):511-518.

[105] Vaughan N, Dubey VN, Wainwright TW, Middleton RG., Can virtual-reality training on orthopaedic simulators improve performance in the operating room?. IEEE Science and Information Conference (SAI) 2015:112.

[106] Simbionix (2012) Arthro Mentor Knee Simulator. Available at: http://simbionix.com/simulators/arthromentor/ (Accessed: 18 December 2015).

[107] Jacobsen ME, Andersen MJ, Hansen CO, Konge L., Testing Basic Competency in Knee Arthroscopy Using a Virtual Reality Simulator, The Journal of Bone \& Joint Surgery 2015, 97(9), 775-81.

[108] VirtaMed (2013) ArthroS ${ }^{\mathrm{TM}}$ Knee and Shoulder Arthoscopy Simulator. Available at: http://www.virtamed.com/en/medical-training-simulators/arthros/ (Accessed: 18 December 2015).

[109] Rasool S, Sourin A, Xia P, Weng B, Kagda F. Towards hand-eye coordination training in virtual knee arthroscopy. In Proceedings of the 19th ACM Symposium on Virtual Reality Software and Technology 2013:1726. 